\title{
Biology-directed and in silico-aided design liberates a potent, simplified and ipomoeassin-F-derived Sec61 inhibitor
}

Sarah O'Keefe ${ }^{1,10, *}$, Pratiti Bhadra ${ }^{2,10}$, Kwabena B. Duah ${ }^{3,4,10}$, Guanghui Zong ${ }^{5,10}$, Levise Tenay ${ }^{2,6}$, Lauren Andrews ${ }^{3}$, Hayden Schneider ${ }^{3}$, Ashley Anderson ${ }^{3}$, Zhijian $\mathrm{Hu}^{7}$, Hazim S. Aljewari ${ }^{8}$, Belinda S. Hall ${ }^{9}$, Rachel E. Simmonds ${ }^{9}$, Volkhard Helms ${ }^{2, *}$, Stephen High ${ }^{1,{ }^{*}}$ and Wei Q. Shi ${ }^{3,11,{ }^{*}}$

${ }^{1}$ School of Biological Sciences, Faculty of Biology, Medicine and Health, University of Manchester, Manchester, M13 9PT, United Kingdom

${ }^{2}$ Center for Bioinformatics, Saarland University, 66123 Saarbrucken, Germany ${ }^{3}$ Department of Chemistry, Ball State University, Muncie, Indiana 47306, USA ${ }^{4}$ Present address: Department of Chemistry, Indiana University, 800 E Kirkwood Ave, Bloomington, IN 47405, USA

${ }^{5}$ Department of Chemistry and Biochemistry, University of Maryland, College Park, Maryland 20742, United States

${ }^{6}$ Department of Biomedical Engineering, Biruni University, 34010

Zeytinburnu/Istanbul, Turkey

${ }^{7}$ Feinstein Institute for Medical Research, Northwell Health, 350 Community Dr., Manhasset, New York, 11030, United States

${ }^{8}$ Ralph E. Martin Department of Chemical Engineering, University of Arkansas, Fayetteville, Arkansas, 72701, United States

${ }^{9}$ Department of Microbial Sciences, School of Biosciences and Medicine, University of Surrey, Guildford, Surrey GU2 7XH, United Kingdom

${ }^{10}$ These authors contributed equally

${ }^{11}$ Lead Contact

${ }^{*}$ Correspondence:

sarah.okeefe@manchester.ac.uk (S.O'K.), rachel.simmonds@surrey.ac.uk (R.E.S), volkhard.helms@bioinformatik.uni-saarland.de (V.H.), stephen.high@manchester.ac.uk (S.H.) and wqshi@bsu.edu (W.Q.S.)

Keywords: cell-free translation, cytotoxicity, endoplasmic reticulum, ipomoeassin F open-chain analogues, medicinal chemistry, molecular docking, protein translocation, Sec61 complex homology modelling, small molecule inhibitors Article character count (with spaces): 37,910 
O'Keefe et al.

\section{Summary}

The macrocyclic small molecule inhibitor ipomoeassin $\mathrm{F}$ (Ipom-F) binds to the central Sec61a subunit of the Sec61 complex and induces cytotoxicity by disrupting multiple aspects of Sec61-mediated protein biogenesis at the endoplasmic reticulum (ER). Here, we show that the integrity of the Ipom- $F$ macrocycle is not required either for Sec61 inhibition in vitro or the induction of cell death, which is abrogated in cells expressing a resistance-conferring Sec61 $\alpha$ mutant. We conclude that Ipom-F and its open-chain analogues interact with Sec61 $\alpha$ via its mycolactone binding site and/or lateral gate, thereby occluding the normal Sec61-mediated pathway for membrane protein insertion at the ER. Using biology-directed and in silico-aided design, we have revolutionised the production of Ipom- $F$ to yield open-chain analogue 3; a potent, simplified and synthetically accessible Ipom-F-derived Sec61 inhibitor. We present 3 as a lead compound for the generation of new protein translocation probes and future therapeutic development.

Summary word count: 147 


\section{Introduction}

The translocation of nascent polypeptides into and across the membrane of the endoplasmic reticulum (ER) is the first and decisive step during the biogenesis of many integral membrane and secretory proteins (Aviram and Schuldiner, 2017; Hegde and Keenan, 2021; O'Keefe et al., 2021a). The Sec61 translocon (Gemmer and Förster, 2020; Voorhees et al., 2014) is the predominant protein conducting channel at the ER membrane, acting as a dynamic hub to co-ordinate the translocation of one third of the cellular proteome in eukaryotes (O'Keefe et al., 2021a). Whilst the fidelity of Sec61-mediated protein translocation is essential for proper cellular and organismal function (Lang et al., 2017; Sicking et al., 2021), small molecule inhibitors that modulate this process have provided valuable insights into the mechanistic complexities of protein translocation at the ER (Gérard et al., 2020; O'Keefe et al., 2021b) and have potential therapeutic applications (Luesch and Paavilainen, 2020; Pauwels et al., 2021).

Small molecule inhibitors typically bind to the central, Sec61a, subunit of the Sec61 translocon (Gérard et al., 2020; Voorhees et al. 2014) and the subsequent blockade in Sec61-mediated protein translocation results in potent cytotoxicity that ultimately, leads to cell death (Gérard et al., 2020; Paatero et al., 2016; Tranter et al., 2020; Zong et al., 2019). The current repertoire of small molecule Sec61 inhibitors includes several structurally distinct classes of natural products: apratoxins (Paatero et al., 2016), coibamide A (Tranter et al., 2020), cotransins (Garrison et al., 2005), decatransin (Junne et al., 2015), ipomoeassin F (Ipom-F) (Zong et al., 2019), mycolactone (Hall et al., 2014; McKenna et al., 2016) and derivatives thereof (for reviews see: Luesch and Paavilainen, 2020; Pauwels et al., 2021). These natural products and their derivatives are substantially more potent than the limited number of synthetic Sec61 inhibitors, the eeyarestatins (Gamayun et al., 2019) and FMP-40139-3 (Klein et al., 2018), that have been identified by library-based screening approaches.

Despite their structural diversity, a common feature shared amongst each of the natural product Sec61 inhibitors is a core, albeit differently sized, cyclic scaffold (Luesch and Paavilainen, 2020; Pauwels et al., 2021). The integrity of most macrocyclic frameworks appears to confer an essential role for efficient Sec61 inhibition, particularly since two linear analogues of coibamide A showed a significant loss in activity when compared to the cyclic parent compound (Hau et al., 2013). 
O'Keefe et al.

Hence, we were surprised when two ring-opened analogues (1 and 2, Figure 1) of the natural product Sec61 inhibitor Ipom-F (Zong et al., 2019) were discovered to still be active in cytotoxicity assays (Zong et al., 2016). In our initial characterization of Sec61 $\alpha$ as the cellular target of Ipom-F (Zong et al., 2019), we additionally used a wellcharacterized cell-free assay to demonstrate that open-chain analogue 2 efficiently inhibits Sec61-mediated protein translocation in vitro (Zong et al., 2019). Thus, in contrast to coibamide A (Hau et al., 2013), opening of the Ipom-F macrocycle does not appear to result in a significant loss of either cytotoxicity or in vitro Sec61 inhibition (Zong et al., 2016; Zong et al., 2019). These results raised the intriguing possibility that Ipom-F could be replaced with highly effective open-chain analogues; potentially revolutionizing both the design and synthesis of future Ipom-F-derived compounds.
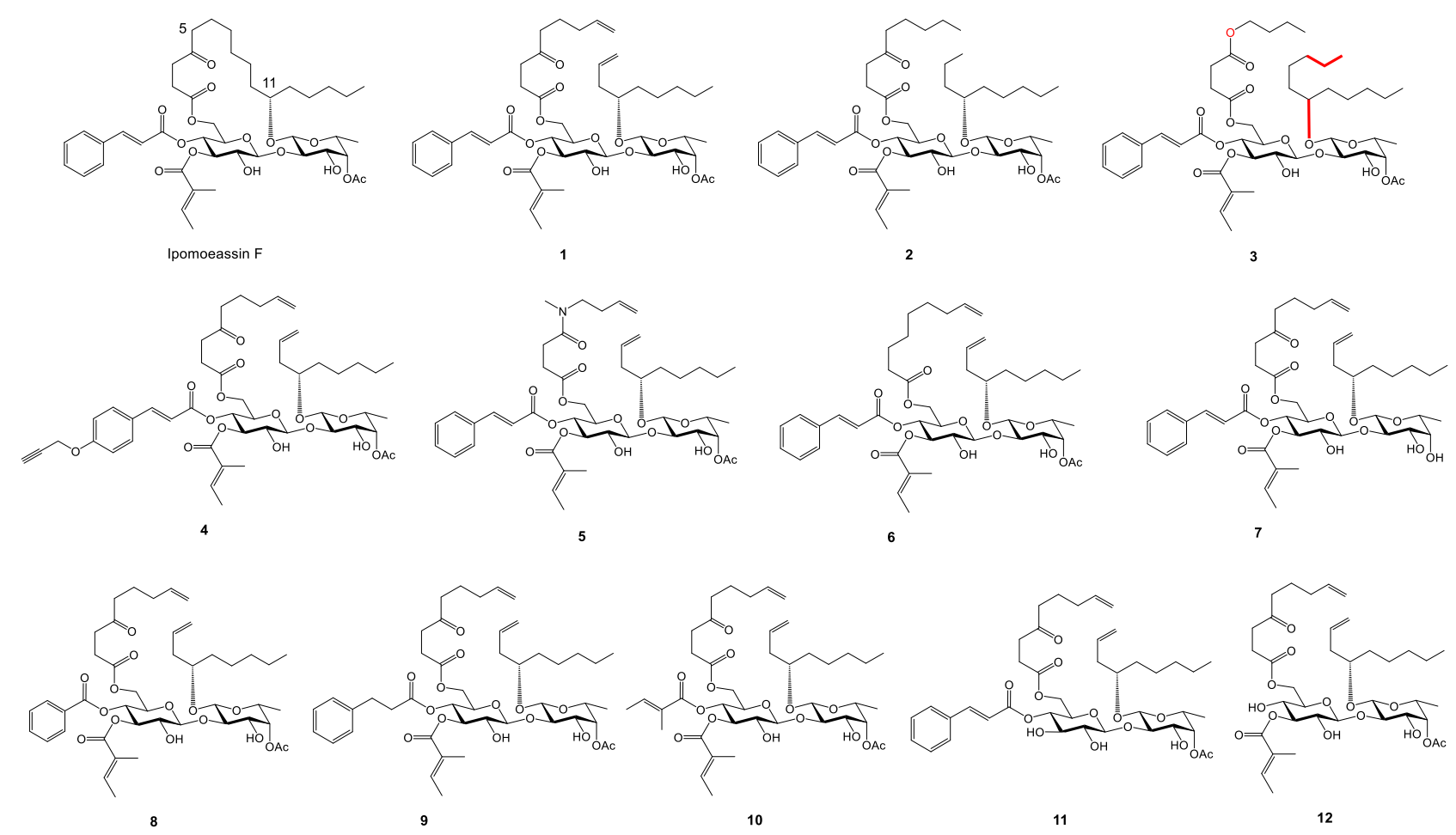

Figure 1: Structures of Ipom-F and its open-chain analogues (1-12).

In this report, we present unambiguous evidence using our established in vitro ER membrane translocation assay in combination with cytotoxicity screening to expand the current scope of ring-modified Ipom-F analogues (Zong et al., 2019; Zong et al., 2020) and prove that open-chain structures can act as authentic surrogates for IpomF. These conclusions are further supported by molecular docking of Ipom-F and analogues within the channel pore of Sec61a (cf. Gérard et al., 2020). We further exploited our in-silico modelling studies in order to design a new and stereochemically 
O'Keefe et al. simpler open-chain Ipom-F analogue 3 (Figure 1) that we predicted to be an active Sec61 inhibitor. After its synthesis, $\mathbf{3}$ was experimentally validated to be almost as effective at inhibiting Sec61-mediated protein translocation as Ipom- $F$ and the parent open-chain analogue 2. We present this active, simplified and synthetically tractable analogue of Ipom- $F$ as a lead compound for the generation of new Ipom-F-derived compounds that can be exploited to further probe the biochemical mechanisms of Sec61-mediated protein translocation at the ER. 


\section{Results}

\section{$\mathrm{NCl} 60$-cell line screen of 1}

To further probe the cytotoxic activity of open-chain analogues, and with a large quantity of analogue 1 already in hand from a previous synthesis (Zong et al., 2016), 1 was submitted to a 60 -cell line screening at the National Cancer Institute (NCI) (Supplementary Information 1). As a result, it was found to be only 4-5-fold less active than Ipom-F $\left(\mathrm{Gl}_{50} \sim 30 \mathrm{nM}\right)$ with an average $\mathrm{Gl}_{50}$ of $\sim 135 \mathrm{nM}$. Further, whilst both compounds did not induce much cytotoxicity in most ovarian cell lines, analogue 1 showed a comparable cytotoxic potency towards the majority of breast and melanoma cell lines when compared to Ipom-F (see Supplementary Information 1). Taken together, these data demonstrate that the macrocylic integrity of Ipom-F is not crucial for cytotoxic activity against the majority of cell lines tested.

\section{Synthesis and cytotoxicity of nine new open-chain analogues}

In light of the cytotoxicity of analogue 1 (Supplementary Information 1), and in order to expand the current scope of ring-opened Ipom-F analogues, nine new open-chain analogues 4-12 (Figure 1) were synthesized (Supplementary Information 2-3). Despite the reduced activity of the di-alkene analogue 1 in comparison to its saturated analogue 2 (Zong et al., 2016), we retained both of the terminal alkenes present in $\mathbf{1}$ to render the preparation of new open-chain analogues more efficient.

Following their successful synthesis, we determined the cytotoxicity of analogues 412 against MDA-MB-231 cells (Table S1). Interestingly, and when compared to $\mathbf{1}$, the methyl amide-modified analogue 5 ( IC $\left._{50} \sim 43 \mathrm{nM}\right)$ showed slightly enhanced activity (IC $50 \sim 59 \mathrm{nM})$, whilst analogues 4 (IC $50 \sim 168 \mathrm{nM})$ and 6 (IC $50 \sim 205 \mathrm{nM})$ showed only a marginal loss in activity (3-4 fold). In contrast, each of the other six open-chain analogues 7-12 showed substantially reduced cytotoxicity towards MDA$\mathrm{MB}-231$ cells ( $\mu \mathrm{M}$ range; > 35-fold activity loss when compared to $\mathbf{1}$ ).

For comparison, we additionally acquired cytotoxicity data for each of the ring-closed analogues 13-21 matching with 4-12 (Figure S1 and Table S1) (Zong et al., 2016; Zong et al., 2017; Zong et al., 2018; Zong et al., 2019); finding good correlation between the cytotoxic activity of each of the new open-chain analogues and their closed-chain counterparts (Figure S2). Taken together, these data suggest that a 
O'Keefe et al.

similar mechanism likely underlies the cytotoxic activity of each of the open- and closed-chain analogues tested.

\section{Open-chain analogues selectively inhibit Sec61-mediated protein translocation} in vitro

Having previously established that the principal molecular basis for the cytotoxicity of Ipom- $F$ is its strong, yet reversible, binding to Sec61 $\alpha$ and the resultant wide-ranging blockade of Sec61-mediated protein translocation at the ER (Zong et al., 2019); we sought evidence that this mechanism also underlies the cytotoxic effects of 1 and other open-chain analogues. Hence, based on our previous characterisation of Ipom$F$ and the open-chain analogue 2 (Zong et al., 2019), we first used a well-established cell-free translation system supplemented with ER microsomes derived from canine pancreas (O'Keefe et al., 2022) to study the effects of the cytotoxic open-chain analogues 1, 2, 5 and 6 (Table S1; Zong et al., 2019) on Sec61-mediated protein translocation in vitro. For comparative purposes, we analyzed the effects of two closed-chain compounds: Ipom-F and the diester-modified analogue 22 (Zong et al., 2018) in parallel (Figure 2A).

Following the resolution of radiolabeled proteins by SDS-PAGE (Figure 2B), we used the efficiency with which the $\mathrm{N}$-terminal domain of the type II integral membrane protein li (short form of HLA class II histocompatibility antigen gamma chain, isoform 1) was $\mathrm{N}$-glycosylated inside the ER lumen as a robust reporter for the authentic membrane integration of this model Sec61-dependent protein client (Figure 2B, right upper panel, OGly versus 2 Gly forms) (Gamayun et al., 2019; Zong et al., 2019; Zong et al., 2020). Based on the reduced levels of the N-glycosylated forms of li synthesized in the presence of $1 \mu \mathrm{M}$ of each compound in comparison to the DMSO control (Figure 2B, right upper panel, lanes 3-8 versus lane 1), Ipom-F and analogues 1, 2, 5 and 22 efficiently, albeit variably, inhibited the in vitro membrane integration of li whilst analogue 6 did not (Figures 2B-C). 
O'Keefe et al.

A

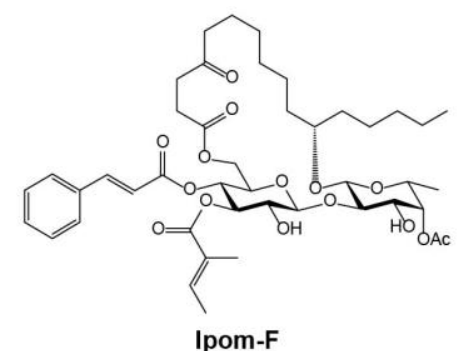

Ipom-F

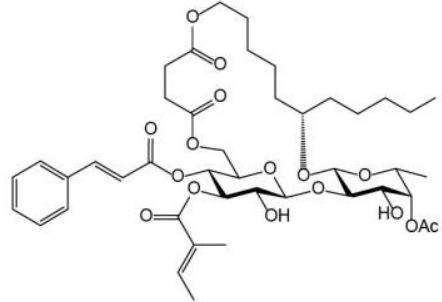

22
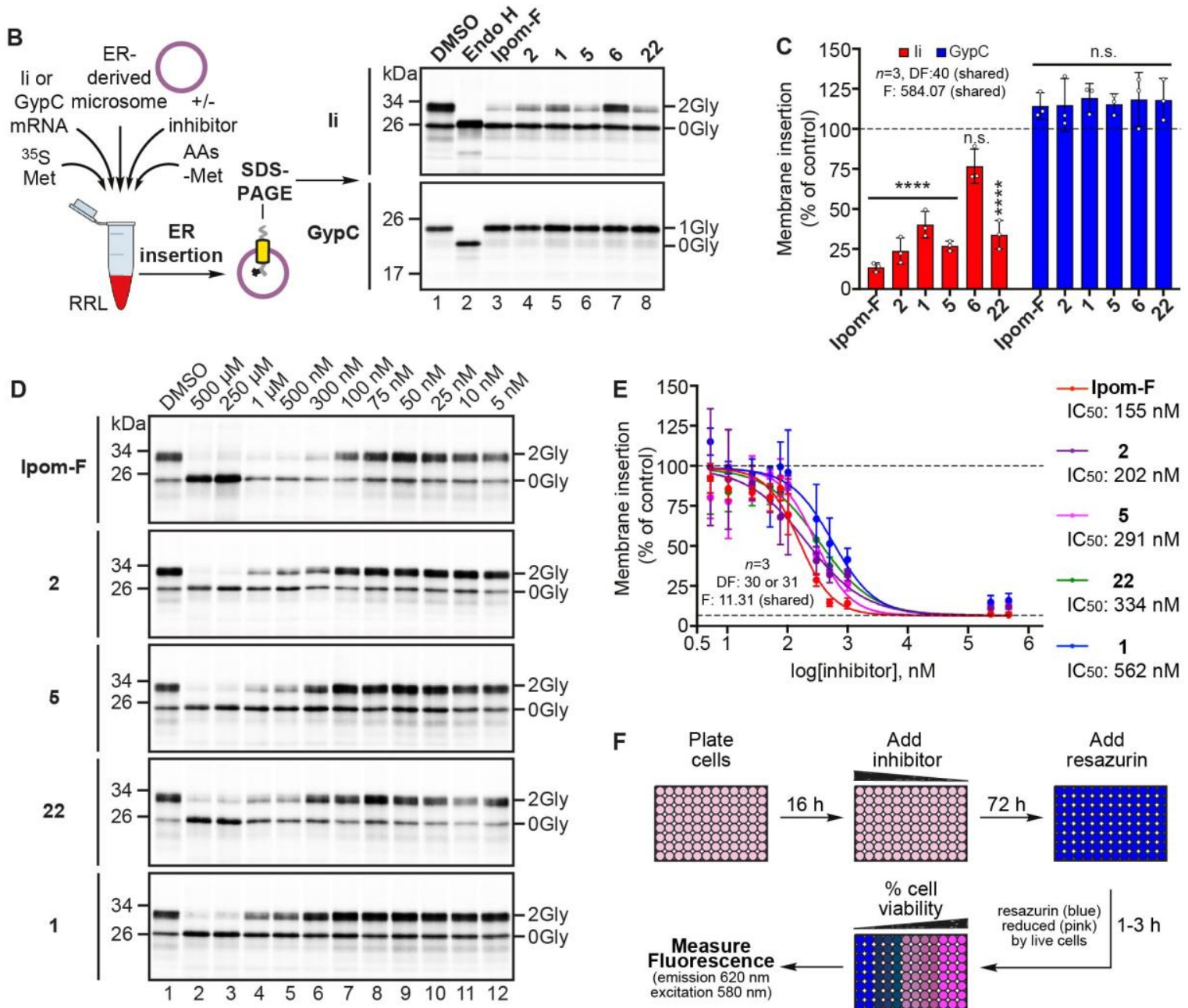

F

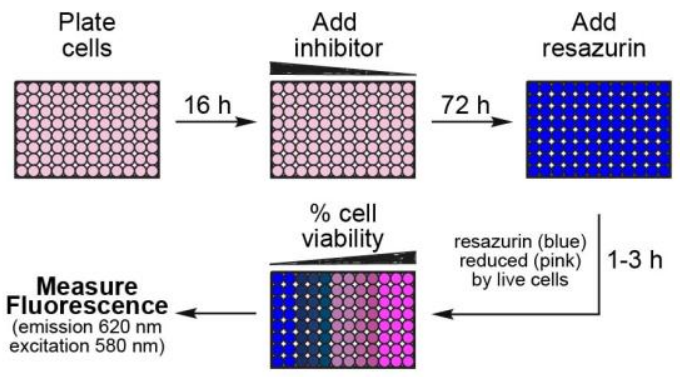

G
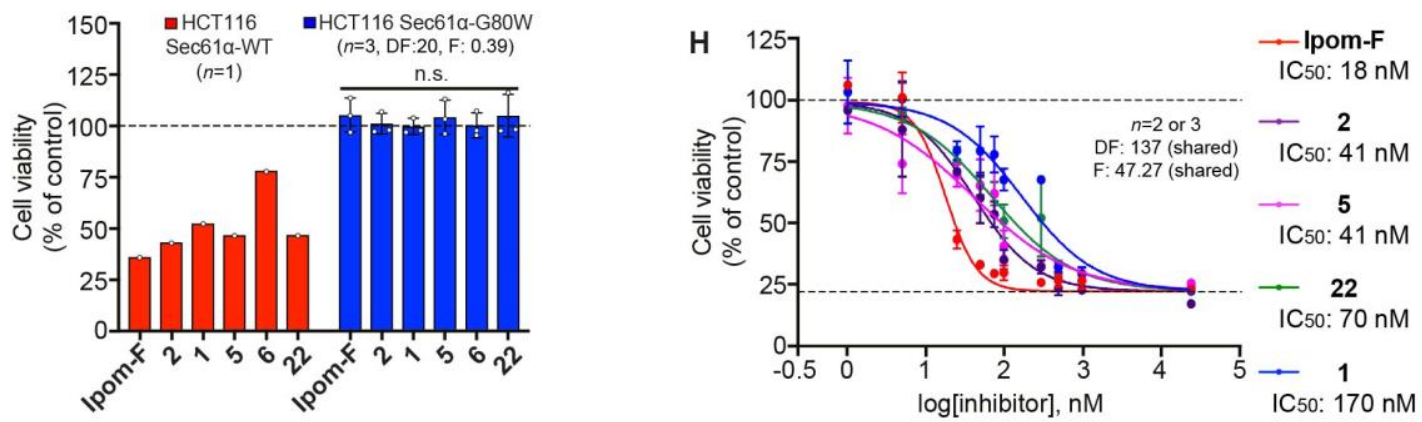

Figure 2: Open-chain Ipom-F analogues selectively inhibit Sec61-mediated protein translocation in vitro and in cellula. A Structures of the ring-closed compounds used as controls for the in vitro and in cellula activity of open-chain analogues; Ipom- $\mathrm{F}$ and its diester analogue 22. B Following translation in the presence or absence of $1 \mu \mathrm{M}$ compound in DMSO, membrane associated radiolabeled precursor proteins of a type II integral membrane protein (li, top panel) and a type III integral membrane protein (GypC, bottom panel) were recovered by centrifugation and analyzed by SDS-PAGE and phosphorimaging. The N-glycosylation of lumenal domains, confirmed by treatment with endoglycosidase $\mathrm{H}$ (Endo $\mathrm{H}$, lane 2), indicates successful membrane translocation and insertion. $\mathbf{C}$ The efficiency of membrane integration was estimated using the ratio of the signal intensity for the $\mathrm{N}$ - 
glycosylated (XGly)/non-glycosylated (0Gly) forms in B and expressed relative to the control (set to $100 \%$ ). Quantifications are given as means \pm SEM for independent membrane insertion experiments performed in triplicate $(n=3$, biologically independent experiments) and statistical significance (twoway ANOVA, DF: 38, F: 584.07) determined using Tukey's multiple comparisons test. Statistical significance is given as n.s., non-significant $P>0.1 ;{ }^{* * \star} P<0.0001$. D Phosphorimages of the membrane-associated products of li synthesised in the presence of $500 \mu \mathrm{M}-5 \mathrm{nM}$ concentrations of Ipom-F and indicated analogues. E Based on the signal intensity depicted in D, and those from two additional independent insertion experiments (data not shown; total $n=3$, biologically independent experiments), $\mathrm{IC}_{50}$ values were estimated using nonlinear regression to fit data to a curve of variable slope (four parameters) using the least-squares fitting methods in which the top and bottom plateaus were defined as $100 \%$ and $7.67 \%$ (the mean of all data at $500 \mu \mathrm{M}$ across all compounds) respectively. F Schematic of the resazurin-based cytotoxicity assay. G Human HCT116 cells (Sec61a-WT; wild-type) and HCT116 cells heterozygous for a SEC61A1 missense mutation encoding G80W (Sec61a-G80W) (Gérard et al., 2020) were treated with $50 \mathrm{nM}$ of Ipom-F or each other compound for $72 \mathrm{~h}$ and cell viability determined using the resazurin-based assay depicted in F. Quantifications normalised to the DMSO control are given either from one experiment ( $n=1$ for HCT116 Sec61a-WT cells) or as means \pm SEM from three independent resazurin-based cytotoxicity screens $(n=3$, biologically independent experiments for HCT116 Sec61a-G80W cells). Statistical significance (ordinary one-way ANOVA, DF: 20, F: 0.39) was determined using Dunnett's multiple comparisons test. H HCT116 Sec61 $\alpha$-WT cells were treated with $25 \mu \mathrm{M}-1 \mathrm{nM}$ concentrations of each compound and cell viability determined as described in F-G. IC 50 values were estimated using nonlinear regression as described in $\mathrm{E}$, with top and bottom plateaus defined as $100 \%$ and $23.70 \%$ (the mean of all data at $25 \mu \mathrm{M}$ across all compounds) respectively. Data were analysed from triplicate (Ipom-F and analogue 22 for $25 \mu \mathrm{M}$ $25 \mathrm{nM}$ concentrations; analogues 1, 2 and 5 for $25 \mu \mathrm{M}-5 \mathrm{nM}$ concentrations) or duplicate (Ipom-F and analogue 22 for 5-1 nM concentrations; analogues 1, 2 and 5 for $1 \mathrm{nM}$ concentration) resazurin-based cytotoxicity screens ( $n=2$ or 3 , biologically independent experiments).

To further analyze the apparent variations in the potency of ring-modified analogues (Figures 2B-C), we next synthesized li in the presence of decreasing (500 $\mu \mathrm{M}-5 \mathrm{nM}$ ) concentrations of each compound that efficiently inhibited the membrane integration of li at $1 \mu \mathrm{M}$ (Figure 1D). Analyses of these in vitro titrations yielded estimated $\mathrm{IC}_{50}$ values in the mid-nanomolar range (Figure 1E), allowing us to rank order compound activity: Ipom-F (IC50: 155 nM) > 2 (IC $50: 202$ nM) > 5 (IC $50: 291$ nM) > 22 (IC $50: 334$ $\mathrm{nM})>1\left(\mathrm{IC}_{50}: 562 \mathrm{nM}\right)>6$ (negligible inhibition at $\left.1 \mu \mathrm{M}\right)$. Given that the two closedchain compounds, Ipom-F and 22 (Figure 2A), are respectively the most and second least potent active inhibitors of Sec61-mediated protein translocation in vitro, these data suggest that a combination of structural and chemical features, and not merely macrocyclic integrity, are important contributors to the potency of Sec61 inhibition.

\section{Open-chain analogues induce cytotoxicity via the selective inhibition of Sec61-} mediated protein translocation

To confirm that Sec61a is the primary target of open-chain analogues and that this interaction underlies their cytotoxic effects, we next used a resazurin-based cell viability assay (Figure $2 \mathrm{~F}$ ) to compare the effects of each compound on the growth of HCT-116 cells that were wild-type for Sec61a (HCT116 Sec61 $\alpha-W T)$ or carrying a heterozygous point mutant in SEC61A1 (HCT116 Sec61a-G80W) that confers 
O'Keefe et al.

resistance to Ipom-F, and reduces binding of mycolactone to the Sec61 translocon by mechanism that involves an alteration in translocon dynamics (Gérard et al., 2020).

Following $72 \mathrm{~h}$ treatment with $50 \mathrm{nM}$ of each compound, Ipom-F and analogues 1, 2, 5 and 22 induced $\sim 48-64 \%$ cell death in HCT116 Sec61 $\alpha$-WT cells whilst, as observed in vitro, analogue 6 was the least potent compound tested ( $20 \%$ cell death; Figure 2G, left). Strikingly, none of the compounds affected the viability of HCT116 Sec61a-G80W cells treated using the same concentration (Figure 2G, right); consistent with Sec61a being their primary molecular target.

To further explore the observed variations in cytotoxicity, we performed cell viability assays using HCT116 Sec61 $\alpha-W T$ cells and decreasing (25 $\mu \mathrm{M}-1 \mathrm{nM})$ concentrations of each compound that efficiently caused cell death at $50 \mathrm{nM}$. Analyses of these in cellula titrations yielded estimated IC 50 values in the low-to-midnanomolar range (Figure $2 \mathrm{H}$ ) allowing us to, once again, rank order compound activity. Although, as typical for Sec61 inhibitors, the IC 50 values derived via cytotoxicity are consistently lower than those obtained by analysing membrane insertion (see Figure S3, cf. Zong et al., 2019; Zong et al., 2020), the cytotoxic potency of each compound closely mirrored the rank order of activity that was observed in vitro. Taken together, these data strongly suggest that, like the closedchain Ipom-F (Zong et al., 2019) and the diester analogue 22, the interaction of active open-chain analogues (1, 2 and 5) with Sec61a and the resultant inhibition of Sec61-mediated protein translocation at the ER underlies their cytotoxic effects.

\section{Molecular docking of open-chain analogues within the channel pore of Sec61a}

We next explored the potential interaction sites and putative docking conformations of active closed-chain (Ipom-F and 22) and open-chain analogues (1, 2, and $\mathbf{5}$ ) in the inhibited state of the Sec61 $\alpha$ channel, using the cryogenic-electron microscopy (cryoEM)-derived structure of the canine Sec61 channel bound to mycolactone as the basis for our modelling (cf. Gérard et al., 2020). These docking results suggest that Ipom- $F$ occupies the same groove between the transmembrane (TM) helices TM2, TM7, TM8 and the cytosolic loop (CL) 4 of Sec61a (Figure 3B) that mycolactone was observed to bind in (Gérard et al., 2020), and that was approximately recovered in a previous docking analysis of mycolactone (Bhadra et al., 2021) using a similar docking protocol 
as used here. The predicted binding affinity of Ipom- $F$ is $7.82 \pm 0.2 \mathrm{kcal} / \mathrm{mol}$ and in this orientation Ipom-F may preferentially interact with the C-terminus of TM2 (Leu89Ala97), the GIn170-Gly172 region of CL4 (loop between TM4-TM5) and the Trp379Val382 region of CL8 (loop between TM8-TM9) (Figure S4A). The D-fucose region of Ipom-F most likely occupies the volume between the TM2 helix and CL4 (Figure 3B), since this region formed a hydrogen bond with side-chain or backbone atoms of GIn170 in CL4 in all of our independent final docking simulation results.

In contrast to Ipom-F, the closed-chain analogue 22 was predicted to bind in two different locations (Figure 3A); in the same groove where Ipom-F and mycolactone bind or in the upper part of the lateral gate (Figure $3 \mathrm{C}$ ), with predicted binding affinities of $-8.81 \pm 0.63$ and $-7.35 \pm 0.23 \mathrm{kcal} / \mathrm{mol}$, respectively. Like Ipom-F, analogue 22 interacts with the C-terminus of the TM2 helix, the CL4 region and CL8 (Figure S4A). However, when positioned in the upper part of the lateral gate it preferentially interacts with TM7 (GIn294-Val298) (Figure S4B).

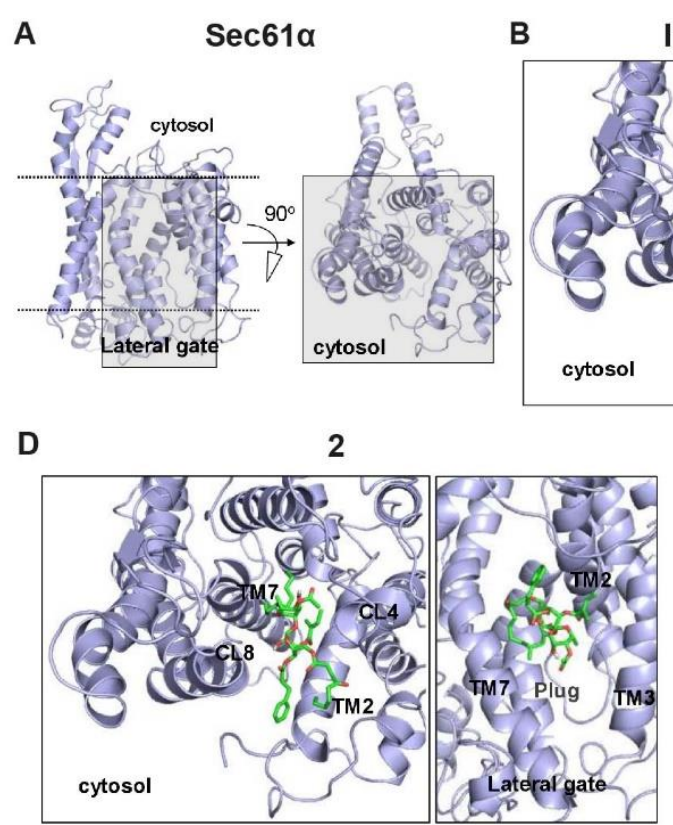

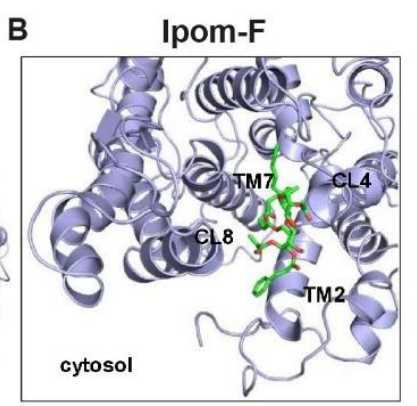

$\mathrm{E}$

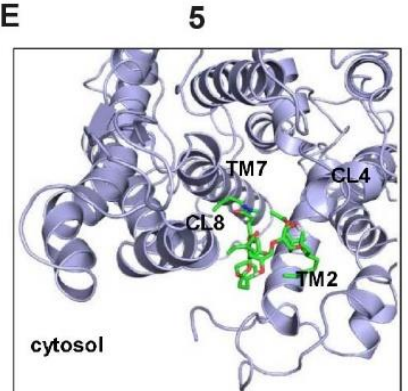

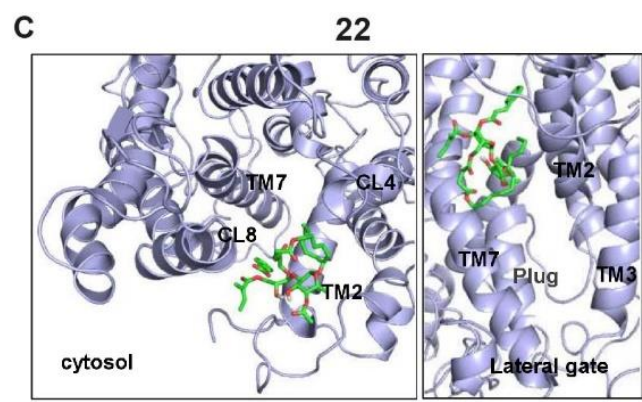

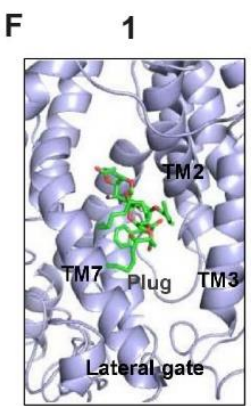

Figure 3: Homology model of human-Sec61a and molecular docking. A Homology model of human-Sec61a in the inhibited state. The two grey boxes indicate two different binding sites of analogues. The 'cytosol' view represents a top-view of Sec61a from the cytosolic side and focuses on the groove between TM2, TM7, CL8 and CL4 whilst the 'lateral gate' view represents a side-view from the lipid bilayer. The other panels show the most favourable docking conformations of closed-chain (B Ipom-F; C 22) and open-chain (D 2; E 5; F 1) analogues in the inhibited conformation of human-Sec61a.

Similar to the closed-chain analogue 22, the open-chain analogue 2 was also predicted to bind in two different locations; namely, in the binding groove of mycolactone (Gérard et al., 2020) and in the middle of the lateral gate with very similar 
O'Keefe et al.

predicted binding affinities of $-4.5 \pm 0.75$ and $-4.4 \pm 0.55 \mathrm{kcal} / \mathrm{mol}$, respectively. As observed for Ipom-F and its closed-chain analogue 22, open-chain analogue 2 also strongly interacts with TM2, CL4 and CL8 when occupying the mycolactone binding site (Figure S4A). Like Ipom-F, analogue 2 is also inclined to hydrogen bond with the CL4 region (Lys171); a hydrogen bond that was identified in four out of five independent docking simulations. However, when occupying the middle of the lateral gate analogue 2 likely interacts with the plug region (lle68), TM3 and TM7 (Figure S4B).

In contrast, analogue 5 was predicted to bind only at the groove of the lpom-F binding site with a predicted binding affinity of $-3.28 \pm 0.9 \mathrm{kcal} / \mathrm{mol}$ where it interacts with the Cterminus of TM2, CL4 and CL8 (see Figure S4A). Likewise, the open-chain analogue 1 only binds in one position; at the lower part of the lateral gate (Figure 3F), with a predicted binding affinity of $-4.25 \pm 0.6 \mathrm{kcal} / \mathrm{mol}$, where it strongly interacts with the plug region (Met65-Ile68), TM3 (Ile123-GIn127) and TM7 (Gln294-Val298) (see Figure S4B).

Taken together, our docking results suggest that, whilst some compounds also show favourable affinities at the lateral gate (cf. 1, 2 and 22), Ipom-F and the majority of the modelled Ipom-F analogues likely share a similar binding site to that identified in the cryo-EM structure of the mycolactone-bound Sec61 complex (Gérard et al., 2020).

\section{Design of analogue 3}

With extensive biological and modelling data in hand, we were keen to design a new Ipom-F-derived lead compound that would be more synthetically accessible than compounds 1 and $\mathbf{2}$ whilst also retaining a comparable level of biological activity. Since the alkene-reduced analogue 2 was the most potent open-chain analogue discovered to date, we first decided to remove both terminal double bonds from the new analogue. Second, and to avoid low-yielding Grignard reactions during the synthesis of the aglycones at the 6"-OH-Glup and C-1'-Fucp positions (Zong et al., 2016), we sought to replace 4-oxononanoic acid with mono-butyl succinate 28 (Scheme 1) in the synthetic route to the new analogue. Such a strategy, whilst synthetically attractive, additionally permits the well-tolerated bioisosteric replacement of the C-5 methylene with an oxygen atom (cf. 22; Table 1) whilst 
retaining the C-4 carbonyl group, whose removal is detrimental to compound potency (cf. 6; Table 1).

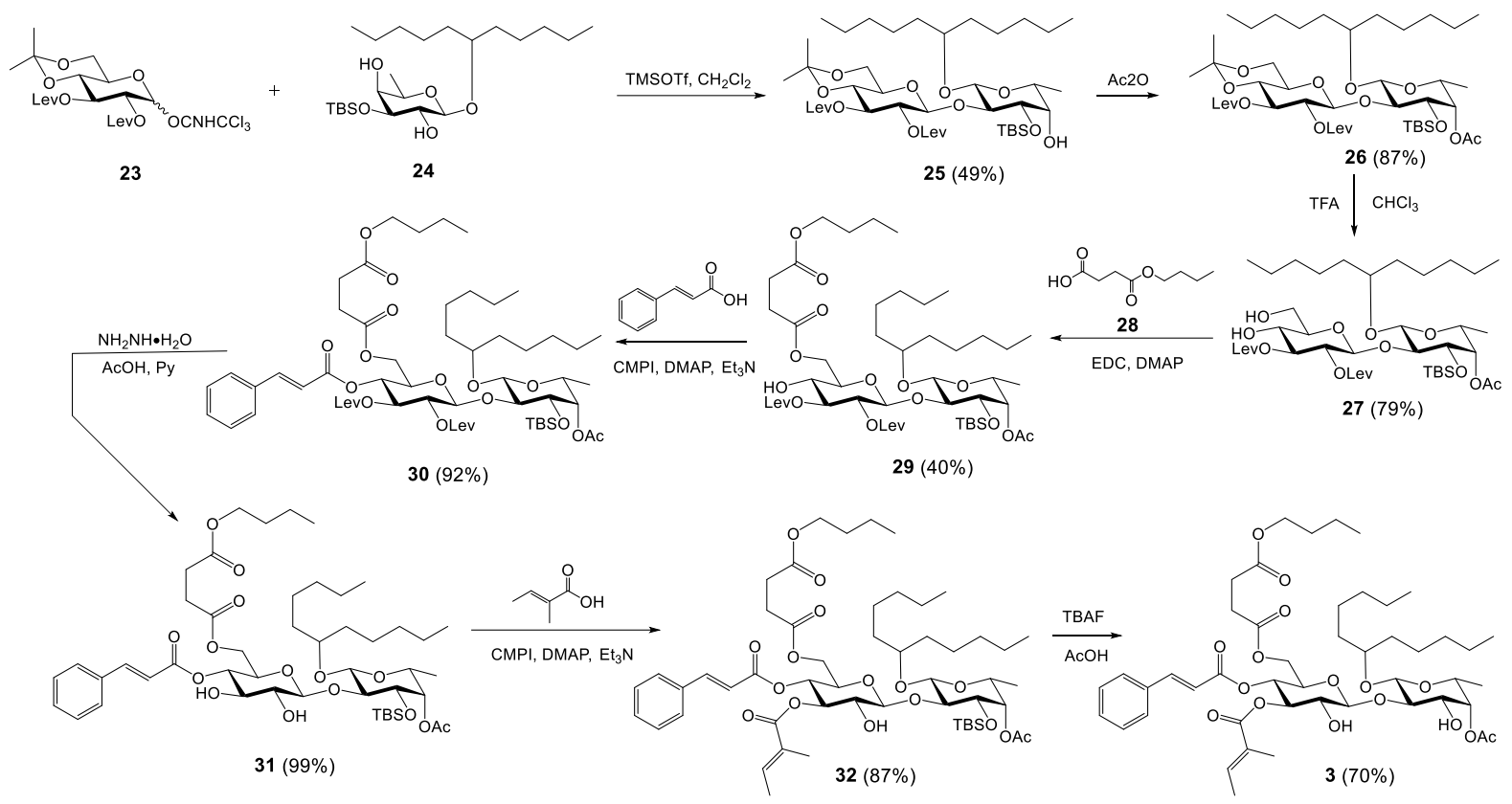

Scheme 1: Syntheses of the rationally designed, new open-chain analogue (3) of Ipom-F.

Lastly, we decided to increase the lipophilicity of the new analogue for two reasons:

i) our earlier studies on how the ring size of closed-chain analogues affects compound potency revealed that ring expansion by two methylene units, and the concomitant increase in lipophilicity, is an advantageous feature (Zong et al., 2020); and ii) in this study, increased compound potency in vitro and in cellula for both the open-chain $(2 \geq 5>1)$ and closed-chain (Ipom-F $>22)$ compounds appears to correlate with an increase in lipophilicity (based on cLogP calculations; Table 1).

Table 1. Comparison of chemical properties, inhibition of in vitro protein translocation (IC $50, n M)$ and cytotoxicity in HCT116 Sec61 $\alpha-W T$ cells $\left(\mathrm{IC}_{50}, \mathrm{nM}\right)$ of Ipom-F and analogues.

\begin{tabular}{|c|c|c|c|c|c|c|}
\hline Compound & $\begin{array}{c}\text { Ring } \\
\text { Integrity }\end{array}$ & $\begin{array}{c}\text { Ring } \\
\text { modification }\end{array}$ & $\begin{array}{c}\text { C-11 } \\
\text { Chirality }\end{array}$ & CLogP $^{\mathbf{a}}$ & $\begin{array}{c}\text { In vitro } \\
\text { translocation } \\
\text { inhibition }\end{array}$ & $\begin{array}{c}\text { Cytotoxicity } \\
\text { HCT-116 cells }\end{array}$ \\
\hline Ipom-F & Closed & None & $11 S$ & 5.97 & 155 & 18 \\
\hline $\mathbf{2}$ & Open & None & $11 S$ & 8.72 & 202 & 41 \\
\hline $\mathbf{5}$ & Open & Dialkene, aza & $11 S$ & 6.98 & 291 & 41 \\
\hline $\mathbf{2 2}$ & Closed & Diester & $11 S$ & 4.94 & 334 & 70 \\
\hline $\mathbf{1}$ & Open & Dialkene & $11 S$ & 7.75 & 562 & 170 \\
\hline $\mathbf{6}$ & Open & $\begin{array}{c}\text { Dialkene, } \\
\text { ketone } \\
\text { removed }\end{array}$ & $11 S$ & 9.39 & Not determined & Not determined \\
& \multicolumn{7}{|l}{} & & & \\
\hline${ }^{a}$ Calculated in ChemDraw.
\end{tabular}


We, therefore, considered the possibility that the chiral starting material (S)-4hydroxy-1-nonene (which requires a 3-step synthesis from an expensive, chiral reagent) could be replaced with a simpler and cheaper alternative; the achiral, but two extra methylene unit-containing, 6-undecanol. Whilst uncertain about how loss of the $11 S$ chiral centre may impact compound potency, we postulated that the increased lipophilicity from the extra two methylene units may compensate for the likely significant loss in activity following its removal (cf. Zong et al., 2015).

To this end, and before embarking on its synthesis, we sought to use molecular docking to evaluate the potential interactions of the stereochemically simplified and synthetically more accessible open-chain analogue 3 in the inhibited state of the Sec61 $\alpha$ channel pore (cf. Figures 3 and S4). Due to the limitation on the number of rotatable bonds that can be considered (maximum of 32 in AutoDock4.2), we docked the closely related compounds $\mathbf{3 a}$ and $\mathbf{3 b}$ instead (Figure $4 \mathrm{~A}$; respectively 32 and $\mathbf{3 1}$ rotatable bonds, with and without the $11 S$ chiral center). Like the open-chain analogue 2, both analogues are predicted to bind in the mycolactone binding site and in the middle of the lateral gate (Figure 4B). Similar to other compounds, and when positioned at the groove of mycolactone, $\mathbf{3 a}$ and $\mathbf{3 b}$ preferentially interact with the TM2, TM7, CL4 and CL8 regions of Sec61a (Figures S4A and S4C) with predicted binding affinities of $-4.15 \pm 0.6 \mathrm{kcal} / \mathrm{mol}$ and $-4.78 \pm 0.6 \mathrm{kcal} / \mathrm{mol}$, respectively. Similar to Ipom-F and analogue 2, 3b preferentially forms hydrogen bonds with Gln170 and Lys171 in the CL4 region and a hydrogen bond was identified in four out of five independent docking simulations. In contrast to $\mathbf{3 b}$, hydrogen bonding between $\mathbf{3 a}$ and the CL4 region (GIn170 and Lys171) was only observed in two out of five independent docking simulations. This suggests that $\mathbf{3 b}$ interacts more strongly with CL4 than $\mathbf{3 a}$.

When bound in the middle of the lateral gate, both analogues are predicted to be in contact with the plug region, TM2, TM3 and TM7 (Figures S4B and S4C) with binding affinities of $-4.7 \pm 0.2 \mathrm{kcal} / \mathrm{mol}$ and $-5.26 \pm 0.9 \mathrm{kcal} / \mathrm{mol}$, respectively. Furthermore, both analogues form hydrogen bonds (observed in four out of five independent docking simulations) with Thr86 (TM2) and Gln127 (TM3) when bound at the lateral gate. In that position, the open-chain analogue 2 also likely forms a hydrogen bond with Thr86 (TM2), whilst this bond was not observed in any docking simulation for closed-chain analogue 22. 
Taken together, our molecular docking studies suggested that, when compared to $\mathbf{3 a}$, loss of the $11 S$ chiral center results in a more favourable interaction of $\mathbf{3 b}$ with Sec61a in the mycolactone binding site and when at middle of the lateral gate. Thus, we elected to remove the $11 S$ center, increase the lipophilicity of the fatty acid region and bioisosterically replace the C-5 methylene with an oxygen atom in our newly designed open-chain analogue 3.

A

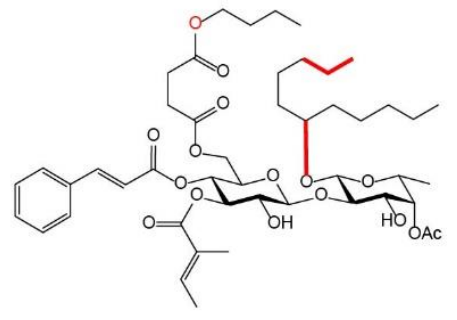

3

non-chiral C-11

33 rotatable bonds cLogP 9.54

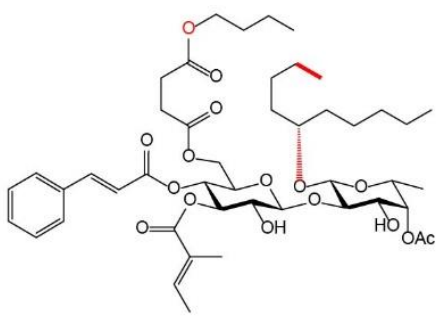

$3 a$

32 rotatable bonds cLogP 9.01

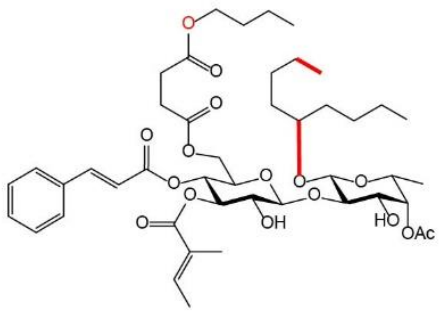

3b

non-chiral C-11

31 rotatable bonds cLogP 8.48

B

3a
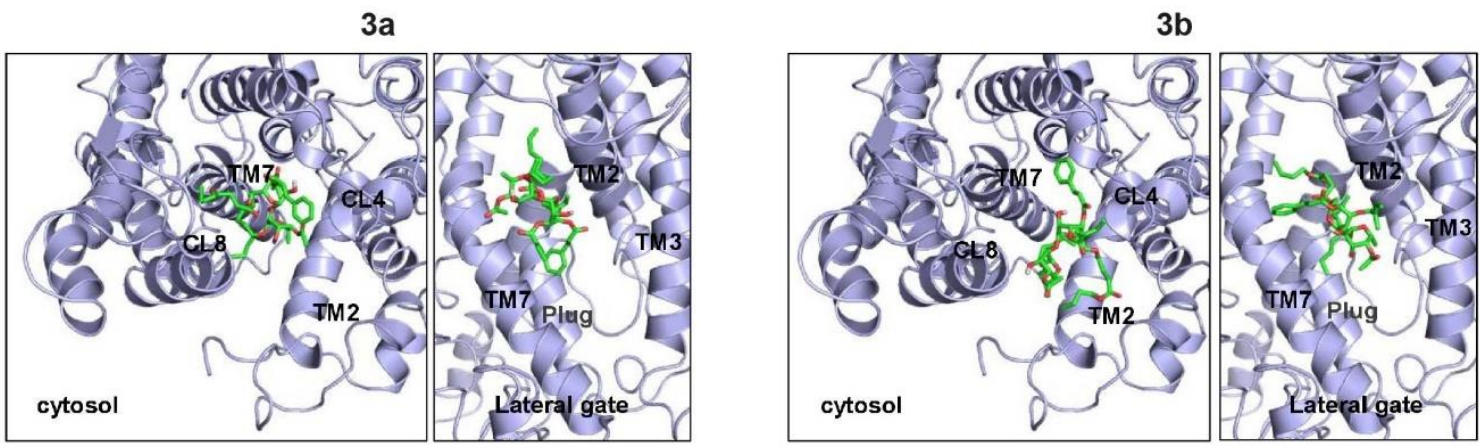

Figure 4: Molecular docking of $3 a$ and $3 b$. A Structures of the closely related open-chain analogues $\mathbf{3}, \mathbf{3 a}$ and $\mathbf{3 b}$, which differ in C-11 chirality, number of rotatable bonds and lipophilicity. CLogP values were calculated in ChemDraw. B The most favourable docking conformations of $\mathbf{3 a}$ and $\mathbf{3 b}$ in the inhibited conformation of human-Sec61a. The 'cytosol' view represents a top-view of Sec61a from the cytosolic side and focuses on the groove between TM2, TM7, CL8 and CL4 whilst the 'lateral gate' view represents a side-view from the lipid bilayer. The homology model of human-Sec61a in the inhibited state used for docking is shown in Figure 3A.

\section{Synthesis of analogue 3}

Our synthesis of analogue 3 (Scheme 1) started with the known trichloroacetimidate glucosyl donor 23 (Zong et al., 2020) and the diol fucoside acceptor 24 (see Supplemental Information 2-3). Regioselective glycosylation on 2-OH-Fucp afforded the monohydroxy intermediate 25 in moderate yield and, after acetylation of the free 4'-OH-Fucp in 25 with acetic anhydride, the isopropylidene protecting group was removed by trifluoroacetic acid to give 4",6"-diol 27. EDC-mediated Steglich esterification of 6"-OH-Glup with mono-butyl succinate 28 (see Supplemental Information 2) successfully produced a second monohydroxy intermediate 29 despite somewhat poor regioselectivity. The cinnamate moiety was then introduced to $4-\mathrm{OH}$ - 
O'Keefe et al.

Glup by the Mukaiyama reagent, 2-chloro-1-methylpyridinium iodide (CMPI), to give the intermediate $\mathbf{3 0}$ in excellent yield. Subsequently, both levulinoyl (Lev) groups were removed by hydrazine under buffered conditions (Yang et al., 2013; Zong et al., 2020). In the penultimate step, the tiglate moiety was selectively introduced to 3 "$\mathrm{OH}-$ Glup in 31 using CMPI to give the intermediate 32 in good yield. Finally, the TBS (tert-butyldimethylsilyl) group at 3'-OH-Fucp was cleaved using TBAF and acetic acid in THF to give the target molecule 3 .

\section{Analogue 3 inhibits Sec61-mediated protein translocation with potency and selectivity comparable to Ipom-F and 2}

To biologically evaluate the activity of our medicinal chemistry and in silico-designed new open-chain analogue 3 , we first analyzed its effects on the in vitro membrane integration of our two model protein substrates, li and GypC (cf. Figure 2B-C). In the first instance, $1 \mu \mathrm{M}$ analogue 3 inhibited the membrane integration of li (Figure 5A, lane 4 versus lane 1) to a level comparable to that of Ipom-F, 2 and 5 (circa 73 $86 \%$ reduction in li membrane integration; Figures $2 \mathrm{~B}-\mathrm{C}$ and $5 \mathrm{~A}-\mathrm{B}$ ). In the second instance, the same concentration of analogue 3 did not affect the membrane integration of GypC (Figure 5A, lanes 13-14 and Figure 5B); confirming the selective inhibition of Sec61-mediated protein translocation by analogue 3 in ER-derived microsomes. Thus, we proceeded to determine the estimated $\mathrm{IC}_{50}$ of analogue 3 on the in vitro membrane integration of $\mathrm{Ii}$ (Figure 2B, lanes 1-12, Figure 2D and Figure S3) which allowed us to rank order analogue 3 as the third most potent compound of the seven tested in this study: Ipom-F (IC50: $155 \mathrm{nM})>\mathbf{2}\left(\mathrm{IC}_{50}: 202 \mathrm{nM}\right)>\mathbf{3}\left(\mathrm{IC}_{50}\right.$ : $242 \mathrm{nM})>5\left(\mathrm{IC}_{50}: 291 \mathrm{nM}\right)>22\left(\mathrm{IC}_{50}: 334 \mathrm{nM}\right)>1\left(\mathrm{IC}_{50}: 562 \mathrm{nM}\right)>6$ (negligible inhibition at $1 \mu \mathrm{M})$.

When we analyzed analogue 3 in our resazurin-based cell viability assay (cf. Figure 2F) using HCT116 Sec61-WT cells (Figures 5D-5E and Figure S3) we found it to be the second most cytotoxic compound of the six that we performed $\mathrm{IC}_{50}$ analyses for: Ipom-F $\left(I_{50}: 18 \mathrm{nM}\right)>3\left(\mathrm{IC}_{50}: 40 \mathrm{nM}\right)>2\left(\mathrm{IC}_{50}: 41 \mathrm{nM}\right)=5\left(\mathrm{IC}_{50}: 41 \mathrm{nM}\right)>22\left(\mathrm{IC}_{50}\right.$ : $70 \mathrm{nM})>1\left(\mathrm{IC}_{50}: 170 \mathrm{nM}\right)$. Further, and as anticipated, cell death was not observed in resistance-conferring HCT116 Sec61-G80W mutant cells treated with the same concentration of analogue 3 that induced $~ 58 \%$ cell death in HCT116 Sec61-WT cells (Figure 5D). We, therefore, conclude that our chosen combination of advantageous chemical features permits the macrocyclic ring opening and removal 
of the $11 S$ chiral center of Ipom-F without a significant loss in the potency or selectivity of the inhibition of Sec61-mediated protein translocation at the ER.
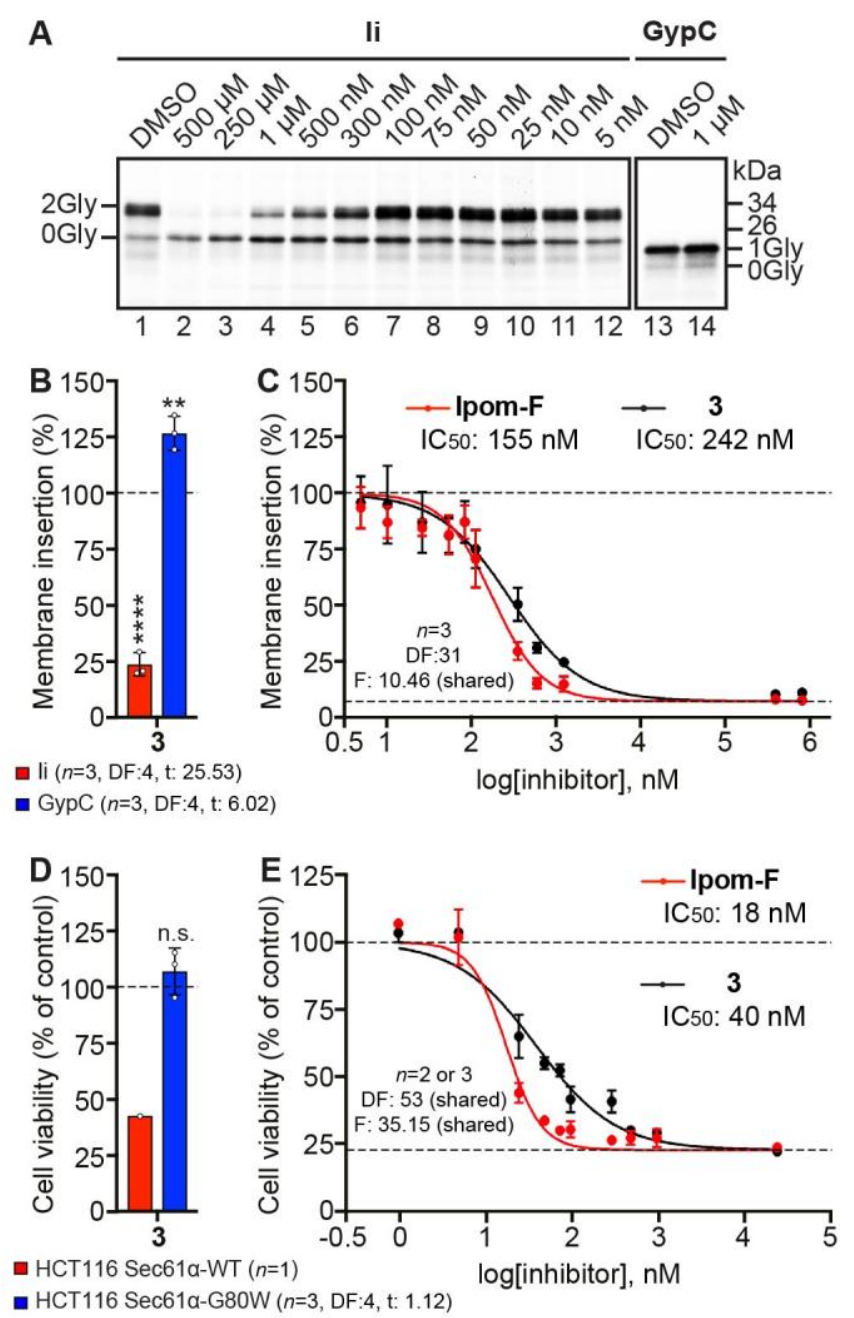

Figure 5: Analogue 3 inhibits Sec61-mediated protein translocation with potency and selectivity comparable to Ipom-F and 2. A Phosphorimages of the membrane associated products of li (lanes 1-12) and GypC (lanes 13-14) synthesised in the absence and presence of $500 \mu \mathrm{M}-5 \mathrm{nM}$ concentrations of analogue 3. B The efficiency of li and GypC membrane integration in the presence of $1 \mu \mathrm{M} 3$ was estimated as described in the legend to Figure 2 and statistical significance was determined using separate unpaired $t$ tests for $\mathrm{li}$ and GypC. $\mathbf{C}$ The IC $5_{50}$ value of $\mathbf{3}$ derived from three independent insertion experiments performed in triplicate $(n=3$, biologically independent experiments) was estimated as described in the legend to Figure 2 and compared to that of Ipom- $F$ (also shown in Figure 2E). D HCT116 Sec61a-WT and HCT116 Sec61a-G80W cells were treated with $50 \mathrm{nM} 3$ and cell viability determined using the resazurin-based cytotoxicity assay described in the legend to Figure 2. Quantifications normalised to the DMSO control are given either from one experiment ( $n=1$ for HCT116 Sec61 $\alpha$-WT cells) or as means \pm SEM for independent resazurin-based cytotoxicity screens performed in triplicate $(n=3$, biologically independent experiments for HCT116 Sec61a-G80W cells). Statistical significance was determined using an unpaired t test. $\mathbf{E}$ The $\mathrm{IC}_{50}$ value of 3 derived from independent resazurin-based cytotoxicity experiments performed in triplicate ( $25 \mu \mathrm{M}-25 \mathrm{nM}$ concentrations) or duplicate (5-1 nM concentrations) was estimated as described in the legend to Figure 2 and compared to that of Ipom-F (also shown in Figure $2 \mathrm{~F}$ ). 


\section{Discussion}

Here, we report comprehensive biology-directed and in silico-aided studies to expand the scope of ring-modified Ipom- $\mathrm{F}$ analogues and understand the molecular basis for the cytotoxicity and in vitro Sec61 inhibition of the ring-opened analogues $\mathbf{1}$ and $\mathbf{2}$ (Zong et al., 2016; Zong et al., 2019). By synthesizing nine new open-chain analogues (4-12), analyzing the effects of selected compounds on cytotoxicity in different cell lines, in vitro Sec61 inhibition and modelling their putative docking conformations within the inhibited state of the pore of the Sec61 $\alpha$ channel, we provide compelling evidence that ring-opened structures can act as authentic surrogates for Ipom-F; a rather unique property when compared to certain series of small molecule Sec61 inhibitors whose macrocylic integrity is crucial for inhibitory activity (Hau et al., 2013).

The impact of ring-opening was first investigated by $\mathrm{NCl}$ 60-cell line screening of 1 and by determining the cytotoxicity of the newly synthesized Ipom- $F$ analogues 4-12 against MDA-MB-231 cells (Table S1). When compared to Ipom- $F$, only a 4-5-fold ( $\mathrm{NCl} 60$-cell line: average $\mathrm{Gl}_{50} \sim 135 \mathrm{nM}$ versus $\sim 30 \mathrm{nM}$ ) and 9-fold (MDA-MB-231 cells: IC $50 \sim 60 \mathrm{nM}$ versus $\sim 7 \mathrm{nM}$ ) loss in potency was observed for the ring-opened analogue 1 , whilst the majority of the nine new open-chain analogues showed modest reductions in cytotoxic potency against MDA-MB-231 cells when compared to their direct closed-chain counterparts (Figure S2).

Thus, we next analyzed the ability of the open-chain analogues that were most cytotoxic in MDA-MB-231 cells (analogues $5>\mathbf{1}>\mathbf{6}$ ) to inhibit the Sec61-mediated membrane integration of li in vitro and via a resazurin-based cell viability assay using HCT116 Sec61a-WT cells (Figure 2). Strikingly, and after benchmarking their activity against the effects of Ipom- $F$, the rank order potency of the compounds tested was comparable in vitro, using HCT116 Sec61a-WT cells and MDA-MB-231 cells (Ipom-F $>2 \geq 5>22>1>6$ ). Further, the lack of any discernible effect of any of the compounds tested on the in vitro membrane integration of GypC or the cell viability of HCT116 Sec61a-G80W Ipom-F resistance-conferring mutant cells (cf. Figure 2; Gérard et al., 2020) are entirely consistent with Sec61 $\alpha$ as the primary molecular target of open-chain analogues.

We have previously postulated that Ipom-F most likely occludes membrane access via the Sec61 lateral gate (O'Keefe et al., 2021; Roboti et al., 2021), as recently 
O'Keefe et al.

established for mycolactone (Gérard et al., 2020). Since the G80W mutation that is located in TM2 of Sec61a confers resistance to both compounds (Gérard et al., 2020) and the Ipom-F-Sec61a binding site is yet to be elucidated, we used the cryo-EM structure of mycolactone-inhibited Sec61 as a model for the molecular docking of Ipom-F and its analogues within the Sec61a channel pore (Figures 3-4). Our docking studies suggest that Ipom-F, the open-chain analogues 2, 5, 3a, 3b and the ester modified closed-chain analogue 22 bind within the same groove as mycolactone (between TM2, TM7, TM8 and CL4 of Sec61a). In addition, analogues 2, 3a, 3b and 22 also show favourable binding affinities at the middle of the lateral gate, whilst the putative docking conformation of $\mathbf{1}$ is exclusively located at the lower part of the lateral gate. Thus, the identification of two Sec61a putative binding sites provides a potential structural rationale as to how the Sec61 complex may accommodate structural modifications in the fatty acid portion of Ipom-F (cf. Zong et al., 2020) and raises the possibility that Ipom-F analogues could be structurally tuned to target distinct Sec61 $\alpha$ binding sites in the future.

Interestingly, and for the compounds that we biologically evaluated, the number of contact residues within the CL4 region reflected the rank order of compound activity observed in vitro and in cellula: Ipom-F = $2 \geq 5>22>1$ (CL4 contact residues: $~ 77 \%$, $77 \%, 62 \%, 31 \%$, 0\% respectively; Figure S4C). Thus, it appears that the interaction of compounds with the CL4 region is important for compound activity, whilst the potential of Ipom-F and 2 to form hydrogen bonds with residues Gln170 and Lys171 in the CL4 region (Figure S4C) may provide the molecular basis for their increased potency when compared to other analogues. Likewise, during the design of analogue 3 , modelling of the closely related compounds $\mathbf{3} \mathbf{a}$ and $\mathbf{3} \mathbf{b}$ suggested that the removal of the $11 \mathrm{~S}$ chiral center resulted in a greater number of contact residues with the CL4 region $(62 \%$ and $77 \%$ respectively) and an increased potential to hydrogen bond with residues GIn170 and Lys171 (Figure S4C). Hence, although we could not model analogue 3 directly, we speculate that it also likely occupies the mycolactone binding site and favourably interacts with the CL4 region.

Whilst the binding affinities of the open-chain Ipom-F analogues $(1:-4.25 \pm 0.6 \mathrm{kcal} / \mathrm{mol}$; 2: $-4.45 \pm 0.5 \mathrm{kcal} / \mathrm{mol} ; 3 \mathbf{a}:-4.15 \pm 0.6 \mathrm{kcal} / \mathrm{mol} ; 3 \mathbf{b}:-4.78 \pm 0.6 \mathrm{kcal} / \mathrm{mol} ; 5:-3.82 \pm 0.6$ $\mathrm{kcal} / \mathrm{mol}$ ) were predicted to be less favorable than those of the closed-chain lpom- $\mathrm{F}$ ($7.82 \pm 0.2 \mathrm{kcal} / \mathrm{mol})$ and $22(-8.09 \pm 0.4 \mathrm{kcal} / \mathrm{mol})$, it should be noted that it is difficult to 
O'Keefe et al.

compare compound docking affinities due to the different entropy changes between the open and closed-chain analogues. Empirical docking scoring functions such as that used in Autodock 4.2 typically approximate entropy penalties on binding using the number of rotatable bonds present in the ligand. Here, the difference in the docking score $(\sim 3 \mathrm{kcal} / \mathrm{mol})$ is associated with the number of rotatable bonds present in the open-chain analogues $\mathbf{1}, \mathbf{2}, \mathbf{3 a}, \mathbf{3 b}$ and $\mathbf{5}$ versus the closed-chain Ipom-F and 22 (respectively 31-32 rotatable bonds versus 15). In the present case, we therefore suggest that the docking score or binding affinity obtained from the docking software should not be considered as an accurate parameter to represent the experimental binding affinity.

Despite these caveats, we nevertheless exploited our biology-directed and in silicoaided studies to design the simplified open-chain analogue 3 which was validated to be almost as effective at inhibiting Sec61-mediated protein translocation as Ipom- $F$ and the parent open-chain analogue 2 (Figure 5). Further, by incorporating the chemically advantageous features gleaned from our $\mathrm{IC}_{50}$ analyses of Ipom-F and analogues 1, 2, 5 and 22 (increased lipophilicity, expansion of the fatty acid portion, retention of the C-4 carbonyl group, bioisosteric replacement of the C-5 methylene with an oxygen atom; see also Table 1), we were able to remove the natural $11 S$ configuration which, until now, has proven crucial for biological activity (cf. Zong et al., 2015). Synthetically, the removal of this chiral center permitted; i) the avoidance lowyielding Grignard reactions during the synthesis of the aglycones at the 6"-OH-Glup and C-1'-Fucp positions (Zong et al., 2016); and ii) the replacement of an expensive chiral starting reagent $((S)-(+)$-epichlorohydrin) with a cheaper and greener non-chiral alternative (6-undecanol, cf. Scheme 1), thus, revolutionising the synthesis of a potent Sec61 inhibitor.

In short, we demonstrate that Ipom-F can be replaced with highly effective open-chain analogues that exert their cytotoxicity by targeting Sec61 $\alpha$ and inhibiting Sec61mediated protein translocation at the ER. By combining in vitro, in cellula and in silico approaches, we have defined the open-chain analogues 2 and $\mathbf{3}$ as Sec61-specific and the most potent acyclic inhibitors of ER protein translocation identified to date. Finally, we present $\mathbf{3}$ as the most simplified and synthetically accessible Ipom-Fderived Sec61 inhibitor discovered thus far. 


\section{Significance}

Small molecules targeting the Sec61 complex have provided novel insights into our understanding of protein translocation at the ER membrane (McKenna et al., 2016; O'Keefe et al., 2021b) and are promising candidates for therapeutic development. Indeed, one Sec61 inhibitor (KZR-261) is currently undergoing phase I clinical development for the treatment of solid tumours (ClinicalTrials.gov: NCT05047536). Since our characterisation of Ipom- $\mathrm{F}$ as a new class of Sec61 inhibitor (Zong et al., 2019), we have highlighted its potential as a broad-spectrum antiviral by defining its effects on viral proteins that commandeer host machineries and mechanisms in order to propagate (O'Keefe et al., 2021c) and demonstrated that Ipom-F and a ringexpanded closed-chain analogue are well tolerated in mice (Zong et al., 2020). We now show that the integrity of the macrocyclic ring of Ipom- $F$ is not required for biological activity and provide compelling in vitro and in cellula evidence that both open and closed-chain Ipom-F analogues induce cytotoxicity by targeting Sec61a and inhibiting Sec61-mediated protein translocation at the ER. Our molecular docking studies suggest that Ipom- $F$ and its analogues likely interact with residues in the CL4 region of Sec61a, where they occupy the same binding site as mycolactone (Gérard et al., 2020), or the Sec61a plug domain when binding at the lateral gate; thereby, opening the way for future in-silico-based drug discovery of Ipom-F-derived Sec61 inhibitors. Finally, our biology-directed and in silico-aided approaches yielded the potent and structurally simplified open-chain analogue $\mathbf{3}$ which lacks the previously crucial natural $11 S$ chiral center. Given its improved synthetic accessibility when compared to Ipom-F, and other classes of Sec61 inhibitors, we anticipate that $\mathbf{3}$ will provide a valuable chemical tool to probe protein translocation at the ER (Gérard et al., 2020; O'Keefe et al., 2021b) and an attractive lead in drug development programs (Pauwels et al., 2021).

Significance word count: $\mathbf{3 0 0}$ 


\section{Acknowledgements}

This work was supported by a Wellcome Trust Investigator Award in Science 202843/Z/16/Z (R.E.S.), a Deutsche Forschungsgemeinschaft (DFG) grant $\mathrm{He}$ 3875/15-1 (V.H.), a Welcome Trust Investigator Award in Science 204957/Z/16/Z (S.H.), an AREA grant GM116032 from the National Institute of General Medical Sciences of the National Institutes of Health $(\mathrm{NIH})$ and the start-up funds from Ball State University (W.Q.S.). We are grateful to Drs Sundeep Rayat and Tykhon Zubkov for their help with the Mass Spectrometry analyses and the HPLC purity tests of analogue 3, respectively. The use of a Thermo Fisher LTQ XL to obtain mass spectrometric data was supported by an NSF MRI grant under CHE-1531851. We also thank the $\mathrm{NCl}$ for their $\mathrm{NCl}-60$ cell line screen analysis of analogue 1 .

\section{Author Contributions}

S.O'K performed the experiments and analyzed the data. P.B. and L.T. performed the in silico analyses. K.B.D. made significant contribution to the synthesis of analogue 3. L.A., H.S. and A.A. also made partial contribution to the synthesis of analogue 3. G.Z. synthesized open-chain analogues 4-12. Z.H. and H.S.A. assayed cytotoxicity of 4-12 against MDA-MB-231 cells. B.S.H. and R.E.S supplied the HCT116 Sec61a-WT and Sec61a-G80W cell lines, and advised on analysis of the viability data. V.H., S.H. and W.Q.S. supervised the experiments. S.O'K., R.E.S., V.H., S.H. and W.Q.S. designed the study. S.O'K., P.B., V.H., S.H. and W.Q.S. wrote the manuscript with the contribution of all authors.

\section{Declaration of Interests}

The authors declare no competing interests. 
Figure Legends

Figure 1: Structures of Ipom-F and its open-chain analogues (1-12).

Figure 2: Open-chain Ipom-F analogues selectively inhibit Sec61-mediated protein translocation in vitro and in cellula.

A Structures of the ring-closed compounds used as controls for the in vitro and in cellula activity of open-chain analogues; Ipom- $\mathrm{F}$ and its diester analogue 22. B Following translation in the presence or absence of $1 \mu \mathrm{M}$ compound in DMSO, membrane associated radiolabeled precursor proteins of a type II integral membrane protein (li, top panel) and a type III integral membrane protein (GypC, bottom panel) were recovered by centrifugation and analyzed by SDS-PAGE and phosphorimaging. The N-glycosylation of lumenal domains, confirmed by treatment with endoglycosidase $\mathrm{H}$ (Endo $\mathrm{H}$, lane 2), indicates successful membrane translocation and insertion. $\mathbf{C}$ The efficiency of membrane integration was estimated using the ratio of the signal intensity for the N-glycosylated (XGly)/non-glycosylated (OGly) forms in $B$ and expressed relative to the control (set to $100 \%$ ). Quantifications are given as means \pm SEM for independent membrane insertion experiments performed in triplicate ( $n=3$, biologically independent experiments) and statistical significance (two-way ANOVA, DF: 38, F: 584.07) determined using Tukey's multiple comparisons test. Statistical significance is given as n.s., non-significant $P>0.1$; ${ }^{* * *} P<0.0001$. D Phosphorimages of the membrane-associated products of li synthesised in the presence of $500 \mu \mathrm{M}-5 \mathrm{nM}$ concentrations of Ipom-F and indicated analogues. E Based on the signal intensity depicted in $\mathrm{D}$, and those from two additional independent insertion experiments (data not shown; total $n=3$, biologically independent experiments), $I C_{50}$ values were estimated using nonlinear regression to fit data to a curve of variable slope (four parameters) using the least-squares fitting methods in which the top and bottom plateaus were defined as $100 \%$ and $7.67 \%$ (the mean of all data at $500 \mu \mathrm{M}$ across all compounds) respectively. $\mathbf{F}$ Schematic of the resazurinbased cytotoxicity assay. G Human HCT116 cells (Sec61a-WT; wild-type) and HCT116 cells heterozygous for a SEC61A1 missense mutation encoding G80W (Sec61a-G80W) (Gérard et al., 2020) were treated with $50 \mathrm{nM}$ of Ipom-F or each other compound for $72 \mathrm{~h}$ and cell viability determined using the resazurin-based assay depicted in F. Quantifications normalised to the DMSO control are given either from one experiment ( $n=1$ for HCT116 Sec61 $\alpha-W T$ cells) or as means \pm SEM from three 
O'Keefe et al.

independent resazurin-based cytotoxicity screens $(n=3$, biologically independent experiments for HCT116 Sec61a-G80W cells). Statistical significance (ordinary oneway ANOVA, DF: 20, F: 0.39) was determined using Dunnett's multiple comparisons test. H HCT116 Sec61 $\alpha-W T$ cells were treated with $25 \mu \mathrm{M}-1 \mathrm{nM}$ concentrations of each compound and cell viability determined as described in F-G. IC 50 values were estimated using nonlinear regression as described in E, with top and bottom plateaus defined as $100 \%$ and $23.70 \%$ (the mean of all data at $25 \mu \mathrm{M}$ across all compounds) respectively. Data were analysed from triplicate (Ipom-F and analogue 22 for $25 \mu \mathrm{M}$ $25 \mathrm{nM}$ concentrations; analogues 1, 2 and 5 for $25 \mu \mathrm{M}-5 \mathrm{nM}$ concentrations) or duplicate (Ipom-F and analogue 22 for 5-1 nM concentrations; analogues 1, 2 and 5 for $1 \mathrm{nM}$ concentration) resazurin-based cytotoxicity screens ( $n=2$ or 3 , biologically independent experiments).

\section{Figure 3: Homology model of human-Sec61a and molecular docking.}

A Homology model of human-Sec61a in the inhibited state. The two grey boxes indicate two different binding sites of analogues. The 'cytosol' view represents a topview of Sec61a from the cytosolic side and focuses on the groove between TM2, TM7, CL8 and CL4 whilst the 'lateral gate' view represents a side-view from the lipid bilayer. The other panels show the most favourable docking conformations of closed-chain (B Ipom-F; C 22) and open-chain (D 2; E 5; F 1) analogues in the inhibited conformation of human-Sec61 $\alpha$.

\section{Scheme 1: Syntheses of the rationally designed, new open-chain analogue (3) of Ipom-F.}

\section{Figure 4: Molecular docking of $3 a$ and $3 b$.}

A Structures of the closely related open-chain analogues $\mathbf{3}, \mathbf{3} \mathbf{a}$ and $\mathbf{3 b}$, which differ in C-11 chirality, number of rotatable bonds and lipophilicity. CLogP values were calculated in ChemDraw. $\mathbf{B}$ The most favourable docking conformations of $\mathbf{3 a}$ and $\mathbf{3 b}$ in the inhibited conformation of human-Sec61a. The 'cytosol' view represents a topview of Sec61 a from the cytosolic side and focuses on the groove between TM2, TM7, CL8 and CL4 whilst the 'lateral gate' view represents a side-view from the lipid bilayer. The homology model of human-Sec61a in the inhibited state used for docking is shown in Figure 3A. 
O'Keefe et al.

Figure 5: Analogue 3 inhibits Sec61-mediated protein translocation with potency and selectivity comparable to Ipom-F and 2.

A Phosphorimages of the membrane associated products of li (lanes 1-12) and GypC (lanes 13-14) synthesised in the absence and presence of $500 \mu \mathrm{M}-5 \mathrm{nM}$ concentrations of analogue 3. B The efficiency of li and GypC membrane integration in the presence of $1 \mu \mathrm{M} 3$ was estimated as described in the legend to Figure 2 and statistical significance was determined using separate unpaired t tests for li and GypC. C The IC $\mathrm{I}_{50}$ value of $\mathbf{3}$ derived from three independent insertion experiments performed in triplicate ( $n=3$, biologically independent experiments) was estimated as described in the legend to Figure 2 and compared to that of Ipom-F (also shown in Figure 2E). D HCT116 Sec61a-WT and HCT116 Sec61a-G80W cells were treated with 50 nM 3 and cell viability determined using the resazurin-based cytotoxicity assay described in the legend to Figure 2. Quantifications normalised to the DMSO control are given either from one experiment ( $n=1$ for HCT116 Sec61a-WT cells) or as means \pm SEM for independent resazurin-based cytotoxicity screens performed in triplicate $(n=3$, biologically independent experiments for HCT116 Sec61a-G80W cells). Statistical significance was determined using an unpaired $t$ test. $\mathbf{E}$ The IC $\mathrm{IC}_{50}$ value of $\mathbf{3}$ derived from independent resazurin-based cytotoxicity experiments performed in triplicate (25 $\mu \mathrm{M}-25 \mathrm{nM}$ concentrations) or duplicate (5-1 $\mathrm{nM}$ concentrations) was estimated as described in the legend to Figure 2 and compared to that of Ipom- $F$ (also shown in Figure 2F). 
O'Keefe et al.

Tables with Titles and Legends

Table 1. Comparison of chemical properties, inhibition of in vitro protein translocation $\left(\mathrm{IC} \mathrm{C}_{50}, \mathrm{nM}\right)$ and cytotoxicity in HCT116 Sec61a-WT cells (IC $\left.50, \mathrm{nM}\right)$ of Ipom-F and analogues

\begin{tabular}{|c|c|c|c|c|c|c|}
\hline Compound & $\begin{array}{c}\text { Ring } \\
\text { Integrity }\end{array}$ & $\begin{array}{c}\text { Ring } \\
\text { modification }\end{array}$ & $\begin{array}{c}\text { C-11 } \\
\text { Chirality }\end{array}$ & cLogPa & $\begin{array}{c}\text { In vitro } \\
\text { translocation } \\
\text { inhibition }\end{array}$ & $\begin{array}{c}\text { Cytotoxicity } \\
\text { HCT-116 cells }\end{array}$ \\
\hline Ipom-F & Closed & None & $11 \mathrm{~S}$ & 5.97 & 155 & 18 \\
\hline 2 & Open & None & $11 S$ & 8.72 & 202 & 41 \\
\hline 5 & Open & Dialkene, aza & $11 S$ & 6.98 & 291 & 41 \\
\hline 22 & Closed & Diester & $11 S$ & 4.94 & 334 & 70 \\
\hline 1 & Open & Dialkene & $11 S$ & 7.75 & 562 & 170 \\
\hline 6 & Open & $\begin{array}{l}\text { Dialkene, } \\
\text { ketone } \\
\text { removed }\end{array}$ & $11 S$ & 9.39 & Not determined & Not determined \\
\hline
\end{tabular}




\section{STAR METHODS}

\section{CONTACT FOR REAGENT AND RESOURCES SHARING}

Further information and requests for resources and reagents should be directed to and will be fulfilled by the lead contact, Wei Q. Shi (W.Q.S).

\section{EXPERIMENTAL MODEL AND SUBJECT DETAILS}

The human breast cancer cell line (MDA-MB-231) was maintained in a DMEM high glucose culture medium supplemented with $10 \%(\mathrm{v} / \mathrm{v})$ fetal bovine serum (FBS) and 2 mM L-glutamine. Parental (Sec61 $\alpha$-WT; Zong et. al., 2019) HCT-116 (human colorectal cancer cells, ATCC, CCL-247) and mutant (Sec61 $\alpha$-G80W; Gérard et al., 2020) HCT-116 cells were maintained in McCoy's 5A (modified) medium (Gibco, cat: 16600 ) supplemented with $10 \%$ (v/v) FBS (Gibco, 10500-064) and 100 units $/ \mathrm{mL}$ penicillin and $100 \mu \mathrm{g} / \mathrm{mL}$ streptomycin (Gibco, cat: 15140-122). All cell lines were maintained in a $5 \% \mathrm{CO}_{2}$ humidified incubator at $37^{\circ} \mathrm{C}$.

\section{METHOD DETAILS}

\section{Biological analysis of compounds}

All compounds from stock solutions in DMSO, or an equivalent volume of DMSO, were included at $5 \%(\mathrm{v} / \mathrm{v})$ in membrane insertion assays or $20 \%(\mathrm{v} / \mathrm{v})$ in cytotoxicity assays.

\section{In vitro membrane insertion assay}

Linear DNA of the short form of human HLA class II histocompatibility antigen gamma chain (li; P04232, isoform 2, residues 17-232) or human glycophorin $C$ (GypC; P04921) were generated by PCR and transcribed into RNA using T7 RNA polymerase (Promega). Membrane insertion assays $\left(20 \mu \mathrm{L}, 1 \mathrm{~h}\right.$ at $30^{\circ} \mathrm{C}$, containing $6.5 \%(\mathrm{v} / \mathrm{v})$ nuclease-treated ER microsomes (from stock with OD280 $=44 / \mathrm{mL}$ )), endoglycosidase $\mathrm{H}_{\mathrm{f}}$ (New England Biolabs) treatment, sample resolution by SDSPAGE (16\% polyacrylamide gels) and gel drying were performed as previously described (Zong et al., 2019; Zong et al., 2020; O'Keefe et al., 2022). Following exposure to a phosphorimaging plate for 24-72 $\mathrm{h}$, radiolabelled products were visualised using a Typhoon FLA-7000 (GE Healthcare) and the ratio of the signal intensity for the $\mathrm{N}$-glycosylated and non-glycosylated forms obtained using AIDA v.5.0 (Raytest Isotopenmeßgeräte). This value was then expressed relative to the matched DMSO control in order to estimate the mean relative insertion ( \pm SEM) from 
O'Keefe et al.

insertion experiments performed in triplicate $(n=3$, biologically independent experiments). IC 50 value estimates were determined in Prism 8 (GraphPad) using nonlinear regression to fit data to a curve of variable slope (four parameters) using the least-squares fitting method, with the top and bottom plateaus of the curve defined as 0 and 100\% respectively (Zong et al., 2019; Zong et al., 2020).

\section{Resazurin-based viability assays}

Cytotoxicity assays were performed in triplicate sets as previously described (Zong et al., 2019; Gérard et al., 2020) and viable cells were counted using an automated cell counter (Bio-Rad TC20) immediately before each experiment. Compound stock solutions in DMSO (10 $\mathrm{mM}$ or $10 \mu \mathrm{M}$ ) were diluted with supplemented culture media (MDA-MB-231 cells: high glucose DMEM; HCT116 Sec61 $\alpha-W T$ and Sec61 $\alpha-G 80 W$ cells: McCoy's (modified) 5A) to make a series of gradient fresh working solutions at equal DMSO percentage immediately prior to each test. First, $100 \mu \mathrm{L}$ of cells at a cell density of $5 \times 10^{4}$ cells $/ \mathrm{mL}$ (MDA-MB-231 cells) or $2.5 \times 10^{4} \mathrm{cells} / \mathrm{mL}$ (Sec61 $\alpha$-WT or Sec61 $\alpha$-G80W HCT-116 cells) were seeded in black 96 -well microtiter plates (Falcon, product $353219 ; 2500$ cells/well) and incubated at $37^{\circ} \mathrm{C}$ for $24 \mathrm{~h}$.

Subsequently, the cells were treated with either $100 \mu \mathrm{L}$ of the freshly made gradient working solution in a total volume of $200 \mu \mathrm{L} /$ well (MDA-MB-231 cells) or $25 \mu \mathrm{L}$ of freshly made gradient in a total volume of $125 \mu \mathrm{L} /$ well (Sec61 $\alpha-\mathrm{WT}$ or Sec61 $\alpha$ G80W HCT-116 cells) at $37^{\circ} \mathrm{C}$ for $72 \mathrm{~h}$. For MDA-MB-231 cells, the media were discarded and $200 \mu \mathrm{L}$ fresh medium containing $10 \%(\mathrm{v} / \mathrm{v})$ alamarBlue HS cell viability reagent (resazurin stock solution) (ThermoFisher, A50100) was added to each well. For Sec61 $\alpha$-WT or Sec61 $\alpha$-G80W HCT-116 cells, the media was not discarded and alamarBlue HS cell viability reagent (resazurin stock solution) (ThermoFisher, A50100) was added to 10\% (v/v). After that, all cells were incubated at $37^{\circ} \mathrm{C}$ for a further $1-3 \mathrm{~h}$ and the emission of each well at $620 \mathrm{~nm}$ was detected using a Synergy H1 Hybrid multi-mode plate reader (BioTek) at excitation $580 \mathrm{~nm}$. The percentage viability compared to the negative control (DMSO-treated cells) was determined and Prism 6 or 8 (GraphPad) used to make a plot of viability (\%) versus sample concentration and to calculate the concentration at which each compound exhibited $50 \%$ cytotoxicity $\left(\mathrm{IC}_{50}\right)$. I $\mathrm{I}_{50}$ value estimates were determined using nonlinear regression to fit data to a curve of variable slope (four parameters). 


\section{Homology modelling and docking protocols}

The 476 amino acid protein sequence of human Sec61a isoform 1 was retrieved from Uniprot (ID: P61619). The crystal structure of human Sec61a is not available, however crystal structures of mammalian (canine) Sec61a have been reported (Gérard et al., 2020). Human Sec61a and Sec61a from Canis lupus (Uniprot ID: P38377) share $99.8 \%$ sequence identity. Hence, homology modelling was carried out to generate a three-dimensional conformational model of human Sec61a using a cryo-EM structure of the "inhibited state" of canine Sec61 $\alpha$ as a template. Precisely, we used the cryoEM structure reported in (Gérard et al., 2020) for the inhibited state of canine Sec61 $\alpha$ in the presence of mycolactone (6Z3T with resolution $2.6 \AA$ ). We added structural information for the missing part of 6Z3T by homology modelling based on 2WWB (EM structure with resolution $6.48 \AA$ ) (Becker et al., 2009). The combined structure using $6 Z 3 T$ and 2WWB was used as template for human Sec61 $\alpha$ in homology modelling that was performed using MODELLER 9.21 (Fiser et al., 2003). After sequence alignment of target and template, MODELLER 9.21 was run locally with the automodel class to generate 50 different models. The model with the lowest DOPE score was selected as the final model and subjected to 1000 steps of energy minimization, using the GROMACS package (version 5.0.7) (Van Der Spoel et al., 2005) to relax side chain atoms. All compounds were modelled using structures drawn in ChemDraw Professional (CambridgeSoft).

Docking of compounds was conducted using AutoDock4.2 (Morris et al., 2009) to predict energetically favourable binding poses of the compound inside or on the surface of human Sec61 $\alpha$. The docking calculations were performed in two consecutive steps. In the first docking step, we adopted a relatively large grid box (100 $\AA \times 100 \AA \times 126 \AA$ ) covering the entire cavity of Sec61a, because the binding site(s) of these compounds are unknown. The Lamarckian genetic algorithm was employed with a population size of 150, $27 \times 10^{3}$ generations and $25 \times 10^{5}$ energy evaluations. All other docking parameters were set to the default values of AutoDock4.2. 1000 individual docking results were clustered according to a threshold for structural similarity of $2.0 \AA$ RMSD. In each cluster, the representative conformation was set to the one with the lowest binding free energy for that cluster. Three independent sets of 1000 docking runs each were conducted in the first stage. 
In the second docking stage, the size of the grid box was scaled down based on the population of the most stable binding positions of each compound. In this finer run, more stringent parameters were used; namely cubic boxes of $86 \AA$ × $86 \AA$ × $70 \AA$, 0.5 $\times 10^{6}$ generations and $100 \times 10^{6}$ energy evaluations. At this stage, we executed five independent fine docking runs yielding 50 docking results each. These 50 conformations were clustered similarly to those reported in a related docking study involving mycolactone (Bhadra et al., 2021). The most favourable conformation of the Sec61a-analogue complex with lowest binding affinity score was selected for further analysis and considered as the final docking pose. Hydrogen bonding and contact residues $(\leq 4 \AA)$ were identified by LigPlot+ (Laskowski et al., 2011) using default parameters.

\section{QUANTIFICATION AND STATISTICAL ANALYSIS}

Quantification procedures used in in vitro and in cellula experiments are described in Method Details. The statistical significance of in vitro and in cellula data with respect to DMSO controls was determined using Tukey's or Dunnett's multiple comparison tests (Figure 2) or unpaired t tests (Figure 5) as indicated in the corresponding figure legends. Statistical significance is given as n.s., non-significant $P>0.1$; * $P<0.05$; ${ }^{* *}, \mathrm{P}<0.01 ;{ }^{* *}, \mathrm{P}<0.001$ and ${ }^{* * *}, \mathrm{P}<0.0001$.

\section{DATA AND SOFTWARE AVAILABILITY}

In vitro data was analyzed with AIDA v5.0. Homology modelling and docking analysis were performed with Modeller v9.24 and Autodock4.2 as described in the previous sections.

\section{KEY RESOURCES TABLE}

\begin{tabular}{|c|c|c|}
\hline REAGENT or RESOURCE & SOURCE & IDENTIFIER \\
\hline \multicolumn{3}{|c|}{ Chemicals, peptides, and recombinant proteins } \\
\hline alamarBlue HS cell viability reagent & ThermoFisher & Cat\# A50100 \\
\hline Amino Acid Mixture Minus Methionine & Promega & Cat\# L996A \\
\hline Compound 1 & Zong et al., 2016 & $\mathrm{~N} / \mathrm{A}$ \\
\hline Compound 2 & $\begin{array}{l}\text { Zong et al., 2016; } \\
\text { Zong et al., 2019 }\end{array}$ & N/A \\
\hline Compound $\mathbf{3}$ & This paper & $\mathrm{N} / \mathrm{A}$ \\
\hline Compound $\mathbf{5}$ & This paper & N/A \\
\hline Compound $\mathbf{6}$ & This paper & $\mathrm{N} / \mathrm{A}$ \\
\hline Compound 22 & Zong et al., 2018 & N/A \\
\hline DMSO & Sigma Aldrich & $\begin{array}{l}\text { Cat\# D8418; CAS: } \\
67-68-5\end{array}$ \\
\hline
\end{tabular}


O'Keefe et al.

\begin{tabular}{|c|c|c|}
\hline EasyTag EXPRESS ${ }^{35}$ S Protein Labeling Mix, [35S] & PerkinElmer & $\begin{array}{l}\text { Cat\# } \\
\text { NEG7720002MC }\end{array}$ \\
\hline Endoglycosidase $\mathrm{H}_{\mathrm{f}}($ Endo $\mathrm{H})$ & New England Biolabs & Cat\# P0703 \\
\hline Fetal bovine serum (FBS) & Gibco & Cat\# 10500-064 \\
\hline Ipom-F & $\begin{array}{l}\text { Zong et al., 2019; } \\
\text { O'Keefe et al., 2021b }\end{array}$ & $\mathrm{N} / \mathrm{A}$ \\
\hline McCoy's 5A (modified) medium & Gibco & Cat\# 16600 \\
\hline Penicillin and streptomycin & Gibco & Cat\# 15140-122 \\
\hline $\begin{array}{l}\text { Puromycin dihydrochloride from Streptomyces } \\
\text { Alboniger }\end{array}$ & Sigma-Aldrich & $\begin{array}{l}\text { Cat\# P7255; CAS: } \\
58-58-2\end{array}$ \\
\hline Reticulocyte Lysate, Nuclease Treated & Promega & L416A \\
\hline Trypan Blue & Sigma-Aldrich & $\begin{array}{l}\text { Cat\# T8154; CAS: } \\
\text { 72-57-1 }\end{array}$ \\
\hline T7 RNA Polymerase & Promega & Cat \# P2075 \\
\hline \multicolumn{3}{|l|}{ Deposited data } \\
\hline Human Sec61 subunit alpha, isoform 1 & & Uniprot ID: P61619 \\
\hline $\begin{array}{l}\text { Cryo-EM structure of the mammalian Sec } 61 \text { complex } \\
\text { bound to the actively translating wheat germ } 80 \mathrm{~S} \\
\text { ribosomes }\end{array}$ & Becker et al., 2009 & PDB: 2WWB \\
\hline Structure of canine Sec61 inhibited by mycolactone & Gérard et al., 2020 & PDB: $6 Z 3 T$ \\
\hline \multicolumn{3}{|l|}{ Experimental models: Cell lines } \\
\hline MDA-MB-231 cells & Zong et al., 2019 & $\mathrm{~N} / \mathrm{A}$ \\
\hline Human: HCT116 cells (Sec61a WT) & ATCC & CCL-247 \\
\hline Human: HCT116 cells (Sec61a G80W) & Gérard et al., 2020 & $\mathrm{~N} / \mathrm{A}$ \\
\hline \multicolumn{3}{|l|}{ Oligonucleotides } \\
\hline $\begin{array}{l}\text { Primer: pGEM3 Forward: } \\
\text { GTGGATAACCGTATTACCGCC }\end{array}$ & $\begin{array}{l}\text { Integrated DNA } \\
\text { Technologies }\end{array}$ & $\mathrm{N} / \mathrm{A}$ \\
\hline $\begin{array}{l}\text { Primer: pGEM3 Reverse: } \\
\text { CTCTGACGGCAGTTTACGAG }\end{array}$ & $\begin{array}{l}\text { Integrated DNA } \\
\text { Technologies }\end{array}$ & $\mathrm{N} / \mathrm{A}$ \\
\hline Primer: li Reverse: GTGGATAACCGTATTACCGCC & $\begin{array}{l}\text { Integrated DNA } \\
\text { Technologies }\end{array}$ & $\mathrm{N} / \mathrm{A}$ \\
\hline \multicolumn{3}{|l|}{ Recombinant DNA } \\
\hline cDNA: pGEM3 li & $\begin{array}{l}\text { Zong et al., 2019; } \\
\text { O'Keefe et al., 2021b }\end{array}$ & $\begin{array}{l}\text { UniProt ID: P04232- } \\
2\end{array}$ \\
\hline cDNA: pGEM4 GypC & $\begin{array}{l}\text { Zong et al., 2019; } \\
\text { O'Keefe et al., 2021b }\end{array}$ & UniProt ID: P04921 \\
\hline \multicolumn{3}{|l|}{ Software and algorithms } \\
\hline Adobe Illustrator 26.0 & Adobe & $\begin{array}{l}\text { https://www.adobe.c } \\
\text { om/uk/creativecloud. } \\
\text { html }\end{array}$ \\
\hline Adobe Photoshop 23.x & Adobe & $\begin{array}{l}\text { https://www.adobe.c } \\
\text { om/uk/creativecloud. } \\
\text { html }\end{array}$ \\
\hline AIDA v5.0 & Elysia Raytest & $\begin{array}{l}\text { http://www.elysia- } \\
\text { raytest.com/de/catal } \\
\text { oglight/ }\end{array}$ \\
\hline AutoDock4.2 & Morris et al., 2009 & $\begin{array}{l}\text { https://autodocksuite } \\
\text {.scripps.edu/autodoc } \\
\text { k4/ }\end{array}$ \\
\hline BioTek Gen5 & Agilent & $\begin{array}{l}\text { https://www.biotek.c } \\
\text { om/products/softwar } \\
\text { e-robotics- } \\
\text { software/gen5- } \\
\text { microplate-reader- } \\
\text { and-imager- } \\
\text { software/ }\end{array}$ \\
\hline
\end{tabular}


O'Keefe et al.

\begin{tabular}{|c|c|c|}
\hline ChemDraw Professional & $\begin{array}{l}\text { CambridgeSoft, Perkin } \\
\text { Elmer }\end{array}$ & $\begin{array}{l}\text { https://perkinelmerinf } \\
\text { ormatics.com/produc } \\
\text { ts/research/chemdra } \\
\text { w/ }\end{array}$ \\
\hline GROMACS package v5.0.7 & $\begin{array}{l}\text { Van Der Spoel et al., } \\
2005\end{array}$ & $\begin{array}{l}\text { http://www.gromacs. } \\
\text { org/Documentation_- } \\
\text { of_outdated_version } \\
\text { s/Installation_Instruc } \\
\text { tions 5.0 }\end{array}$ \\
\hline LigPlot+ & Laskowski et al., 2011 & $\begin{array}{l}\text { https://www.ebi.ac.u } \\
\text { k/thornton- } \\
\text { srv/software/LigPlus/ }\end{array}$ \\
\hline MODELLER v9.21 & Fiser et al., 2003 & $\begin{array}{l}\text { https://salilab.org/mo } \\
\text { deller/download_inst } \\
\text { allation.html }\end{array}$ \\
\hline Prism v8.0 & GraphPad & $\begin{array}{l}\text { https://www.graphpa } \\
\text { d.com/scientific- } \\
\text { software/prism/ }\end{array}$ \\
\hline SnapGene & SnapGene & $\begin{array}{l}\text { https://www.snapgen } \\
\text { e.com/ }\end{array}$ \\
\hline
\end{tabular}

\section{Supplemental Information}

Supplemental Information 1 contains the $\mathrm{NCl}$ 60-cell line screening data of 1.

Supplemental Information 2 includes chemical syntheses and 5 display items:

Figures S1-S4 and Table S1.

Supplemental Information 3 contains compound NMR spectra. 


\section{References}

Aviram, N., and Schuldiner, M. (2017). Targeting and translocation of proteins to the endoplasmic reticulum at a glance. J. Cell Sci. 130, 4079-4085.

Becker, T., Bhushan, S., Jarasch, A., Armache, J.P., Funes, S., Jossinet, F., Gumbart, J., Mielke, T., Berninghausen, O., Schulten, K., and Westhof, E. (2009). Structure of monomeric yeast and mammalian Sec61 complexes interacting with the translating ribosome. Science. 326, 1369-1373.

Bhadra, P., Dos Santos, S., Gamayun, I., Pick, T., Neumann, C., Ogbechi, J., Hall, B.S., Zimmermann, R., Helms, V., Simmonds, R.E., and Cavalié, A. (2021). Mycolactone enhances the $\mathrm{Ca}^{2+}$ leak from endoplasmic reticulum by trapping Sec61 translocons in a $\mathrm{Ca}^{2+}$ permeable state. Biochem. J. 478, 4005-4024.

Fiser, A., and Šali, A. (2003). Modeller: generation and refinement of homology-based protein structure models. Methods Enzymol. 374, 461-491.

Garrison, J. L., Kunkel, E. J., Hegde, R. S., and Taunton, J. (2005). A substratespecific inhibitor of protein translocation into the endoplasmic reticulum. Nature. 436, 285.

Gamayun, I., O’Keefe, S., Pick, T., Klein, M.-C., Nguyen, D., McKibbin, C., Piacenti, M., Williams, H. M., Flitsch, S. L., Whitehead, R. C., Swanton, E., Helms, V., High, S., Zimmermann, R., and Cavalie, A. (2019).' Eeyarestatin Compounds Selectively Enhance Sec61-Mediated $\mathrm{Ca} 2+$ Leakage from the Endoplasmic Reticulum. Cell Chem. Biol. 26, 571-583.

Gérard, S. F., Hall, B. S., Zakim A. M., Corfield, K. A., Mayerhofer, P. U., Costa, C., Whelligan, D. K., Biggin, P. C., Simmonds, R. E., and Higgins, M. K. (2020). Structure of the inhibited state of the Sec translocon. Mol. Cell. 79, 406-415.

Gemmer, M., and Förster, F. (2020). A clearer picture of the ER translocon complex. J. Cell Sci. 133, jcs231340.

Hall, B.S., Hill, K., McKenna, M., Ogbechi, J., High, S., Willis, A.E., and Simmonds, R.E. (2014). The pathogenic mechanism of the Mycobacterium ulcerans virulence factor, mycolactone, depends on blockade of protein translocation into the ER. PLOS Pathog. 10, e1004061.

Hau, A. M., Greenwood, J. A., Löhr, C. V., Serrill, J. D., Proteau, P. J., Ganley, I. G., McPhail K., L., and Ishmael, J. E. (2013). Coibamide A induced mTOR-independent autophagy and cell death in human glioblastoma cells. PLOS ONE 8, e65250.

Hegde, R. S., and Keenan, R. J. (2021). The mechanisms of integral membrane protein biogenesis. Nat. Rev. Mol. Cell Biol. DOI: 10.1038/s41580-021-00413-2.

Junne, T., Wong, J., Studer, C., Aust, T., Bauer, B. W., Beibel, M., Bhullar, B., Bruccoleri, R., Eichenberger, J., Estoppey, D., Hartmann, N., Knapp, B., Krastel, P., Melin, N., Oakeley, E. J., Oberer, L., Riedl, R., Roma, G., Schuierer, S., Petersen, F., Tallarico, J. A., Rapoport, T. A., Spiess, M., and Hoepfner, D. (2015). Decatransin, a new natural product inhibiting protein translocation at the Sec61/SecYEG translocon. J. Cell Sci. 128, 1217-1229. 
Klein, W., Rutz, C., Eckhard, J., Provinciael, B., Specker, E., Neuenschwander, M., Kleinau, G., Scheerer, P., von Kries, J.-P., Nazaré, M., Vermeire, K., and Schülein, R. (2018). Use of a sequential high throughput screening assay to identify novel inhibitors of the eukaryotic SRP-Sec61 targeting/translocation pathway. PLOS One. 13, e0208641.

Lang, S., Pfeffer, S., Lee, P.-H., Cavalíe, A., Helms, V., Förster, F., and Zimmermann, R. (2017). An update on Sec61 channel functions, mechanisms, and related diseases. Front. Physiol. 8, 887.

Laskowski, R.A., and Swindells, M.B. (2011). LigPlot+: multiple ligand-protein interaction diagrams for drug discovery. J. Chem. Inf. Model. 51, 2778-2786.

Luesch, H., and Paavilainen. V.O. (2020). Natural products as modulators of eukaryotic protein secretion. Nat. Prod. Rep. 37, 717-736.

McKenna, M, Simmonds, R. E., and High, S. (2016). Mechanistic insights into the inhibition of Sec61-dependent co- and post-translational translocation by mycolactone. J. Cell Sci., 129, 1404-1415.

Morris, G.M., Huey, R., Lindstrom, W., Sanner, M.F., Belew, R.K., Goodsell, D.S., and Olson, A.J. (2009). AutoDock4 and AutoDockTools4: Automated docking with selective receptor flexibility. J. Comput. Chem. 30, 2785-2791.

O'Keefe, S., Pool, M. R., and High, S. (2021a). Membrane protein biogenesis at the ER: the highways and the byways. FEBS J. DOI: 10.111/febs.15905.

O'Keefe, S., Zong, G., Duah K.B., Andrews, L.E., Shi, W.Q., and High, S. (2021b). An alternative pathway for membrane protein biogenesis at the endoplasmic reticulum. Commun. Biol. 4, 828.

O'Keefe, S., Roboti, P., Duah, K.B., Zong, G., Schneider, H., Shi, W.Q, and High, S. (2021c). Ipomoeassin-F inhibits the in vitro biogenesis of the SARS-CoV-2 spike protein and its host cell receptor. J. Cell Sci. 134, jcs257758.

O'Keefe S., High, S., and Demangel C. (2022). Biochemical and Biological Assays of Mycolactone-Mediated Inhibition of Sec61. In: Pluschke G., Röltgen K. (eds) Mycobacterium ulcerans. Methods in Molecular Biology, vol 2387. Humana, New York, NY. DOI: 10.1007/978-1-0716-1779-3_16.

Paatero, A.O., Kellosalo, J., Dunyak, B.M., Almaliti, J., Gestwicki, J.E., Gerwick, W.H., Taunton, J., and Paavilainen, V.O. (2016). Apratoxin kills cells by direct blockade of the Sec61 protein translocation channel. Cell Chem. Biol. 23, 561-566.

Pauwels, E., Schülein, R., and Vermeire, K. (2021). Inhibitors of the Sec61 complex and novel high throughput screening strategies to target the protein translocation pathway. Int. J. Mol. Sci. 22, 12007.

Roboti, P., O'Keefe, S., Duah, K. B., Shi, W. Q., and High, S. (2021). IpomoeassinF disrupts multiple aspects of secretory protein biogenesis. Sci. Rep. 11, 11562. 
O'Keefe et al.

Sicking, M., Lang, S., Bochen, F., Roos, A., Drenth, J. P. H., Zakaria, M., Zimmermann, R., and Linxweiler, M. (2021). Complexity and specificity of Sec61channelopathies: human diseases affecting gating of the Sec61 complex. Cells. 10, 1036.

Tranter, D., Paatero, A.O., Kawaguchi, S., Kazemi, S., Seriil, J.D., Kellosalo, J., Vogel, W.K., Richter, U., Mattos, D.R., Wan, X., Thornburg, C.C., Oishi, S., McPhail, K.L., Ishmael, J.E., and Paavilainen, V.O. (2020). Coibamide A targets Sec61 to prevent biogenesis of secretory and membrane proteins. A.C.S. Chem. Biol. 15, 2125-2136.

Van der Spoel, D., Lindahl, E., Hess, B., Groenhof, G., Mark, A.E., and Berendsen, H.J. (2005). GROMACS: fast, flexible, and free. J. Comput. Chem. 26, 1701-1718.

Voorhees, R.M., Fernández, I.S., Scheres, S.H.W., and Hegde, R.S. (2014).

Structure of the mammalian ribosomes-Sec61 complex to $3.4 \AA$ resolution. Cell. 157 , 1632-1643.

Yang, Y., Oishi, S., Martin, C. E., and Seeberger, P. H. (2013). Diversity-oriented synthesis of inner core oligosaccharides of the lipopolysaccharide of pathogenic gram-negative bacteria. J. Am. Chem. Soc. 135, 6262-6271.

Zong, G., Barber, E., Aljewari, H., Zhou, J., Hu, Z., Du, Y., and Shi, W. Q. (2015). Total synthesis and biological evaluation of Ipomoeassin $F$ and its unnatural 11Repimer. J. Org. Chem. 80, 9279-9291.

Zong, G., Aljewari, H., Hu, Z., and Shi, W. Q. (2016). Revealing the pharmacophore of Ipomoeassin F through molecular editing. Org. Lett. 18, 1674-1677.

Zong, G., Whisenhunt, L., Hu, Z., and Shi, W. Q. (2017). Synergistic contribution of tiglate and cinnamate to cytotoxicity of ipomoeassin F. J. Org. Chem. 82, 4977-4985.

Zong, G., Sun, X., Bhakta, R., Whisenhunt, L., Hu, Z., Wang, F., and Shi, W. Q. (2018). New insights into structure-activity relationship of Ipomoeassin $F$ from its bioisosteric 5-oxa/aza analogues. Eur. J. Med. Chem. 144, 751-757.

Zong, G., Hu, G., O’Keefe, S., Tranter, D., lannotti, M. J., Baron, L., Hall, B., Corfield, K., Paatero, A. O., Henderson, M. J., Roboti, P., Zhou, J., Sun, X., Govindarajan, M., Rohde, J. M., Blanchard, N., Simmonds, R., Inglese, J., Du, Y., Demangel, C., High, S., Paavilainen, V. O., and Shi, W. Q. (2019). Ipomoeassin F binds Sec61a to inhibit protein translocation. J. Am. Chem. Soc. 141, 8450-8461.

Zong, G., Hu, Z., Duah, K. B., Andrews, L. E., Zhou, J., O’Keefe, S., Whisenhunt, L., Shim, S. J., Du, Y., High, S., and Shi, W. Q. (2020). Ring expansion leads to a more potent analogue of Ipomoeassin F. J. Org. Chem. 85, 16226-16235. 